Article

\title{
An Efficient Memetic Algorithm for the Minimum Load Coloring Problem
}

\author{
Zhiqiang Zhang ${ }^{1,2, * \mathbb{C}}$, Zhongwen $\mathrm{Li}^{1,2, *}$, Xiaobing Qiao ${ }^{3}$ and Weijun Wang ${ }^{2}$ \\ 1 Key Laboratory of Pattern Recognition and Intelligent Information Processing, Institutions of Higher \\ Education of Sichuan Province, Chengdu University, Chengdu 610106, China \\ 2 School of Information Science and Engineering, Chengdu University, Chengdu 610106, China; \\ wangweijun@cdu.edu.cn \\ 3 College of Teachers, Chengdu University, Chengdu 610106, China; qiaoxiaobing@cdu.edu.cn \\ * Correspondence: zqzhang@cdu.edu.cn (Z.Z.); lizw@cdu.edu.cn (Z.L.)
}

Received: 29 March 2019; Accepted: 21 May 2019; Published: 25 May 2019

\begin{abstract}
Given a graph $G$ with $n$ vertices and $l$ edges, the load distribution of a coloring $q: V \rightarrow\{$ red, blue $\}$ is defined as $d_{q}=\left(r_{q}, b_{q}\right)$, in which $r_{q}$ is the number of edges with at least one end-vertex colored red and $b_{q}$ is the number of edges with at least one end-vertex colored blue. The minimum load coloring problem (MLCP) is to find a coloring $q$ such that the maximum load, $l_{q}=1 / l \times \max \left\{r_{q}, b_{q}\right\}$, is minimized. This problem has been proved to be NP-complete. This paper proposes a memetic algorithm for MLCP based on an improved K-OPT local search and an evolutionary operation. Furthermore, a data splitting operation is executed to expand the data amount of global search, and a disturbance operation is employed to improve the search ability of the algorithm. Experiments are carried out on the benchmark DIMACS to compare the searching results from memetic algorithm and the proposed algorithms. The experimental results show that a greater number of best results for the graphs can be found by the memetic algorithm, which can improve the best known results of MLCP.
\end{abstract}

Keywords: minimum load coloring; memetic algorithm; evolutionary; local search

\section{Introduction}

The minimum load coloring problem (MLCP) of the graph, discussed in this paper, was introduced by Nitin Ahuja et al. [1]. This problem is described as follows: a graph $G=(V, E)$ is given, in which $V$ is a set of $n$ vertices, and $E$ is a set of $l$ edges. The load of a $k$-coloring $\varphi: V \rightarrow\{1,2,3, \ldots, k\}$ is defined as

$$
1 / l \times \max _{i \in\{1,2,3 \ldots, k\}}\left|\left\{e \in E \mid \varphi^{-1}(i) \cap e \neq \varnothing\right\}\right|,
$$

the maximum fraction of edges with at least one end-point in color $i$, where the maximum is taken over all $i \in\{1,2,3, \ldots, k\}$. The aim of the minimum load coloring problem is to minimize the load over all $k$-colorings.

This paper is dedicated to the NP-complete minimum load coloring problem [1]. We focus on coloring the vertices with the colors of red and blue. A graph $G=(V, E)$ is given, in which $V$ is a set of $n$ vertices, and $E$ is a set of $l$ edges. The load distribution of a coloring $q: V \rightarrow\{$ red, blue\} is defined as $d_{q}=\left(r_{q}, b_{q}\right)$, in which $r_{q}$ is the number of edges with at least one end-vertex colored red, and $b_{q}$ is the number of edges with at least one end-vertex colored blue. The objective of MLCP is to find a coloring $q$ such that the maximum load, $l_{q}=1 / l \times \max \left\{r_{q}, b_{q}\right\}$, is minimized. MLCP can be applied to solve the wavelength division multiplexing (WDM) problem of network communication, and build the WDM network and complex power network [1-3]. 
This paper proposes an effective memetic algorithm for the minimum load coloring problem, which relies on four key components. Firstly, an improved K-OPT local search procedure, combining a tabu search strategy and a vertices addition strategy, is especially designed for MLCP to explore the search space and escape from the local optima. Secondly, a data splitting operation is used to expand the amount of data in the search space, which enables the memetic algorithm to explore in a larger search space. Thirdly, to find better global results, through randomly changing the current search patterns a disturbance operation is employed to improve the probability of escaping from the local optima. Finally, a population evolution mechanism is devised to determine how the better solution is inserted into the population.

We evaluate the performance of memetic algorithm on 59 well-known graphs from benchmark DIMACS coloring competitions. The computational results show that the search ability of memetic algorithm is better than those of simulated annealing algorithm, greedy algorithm, artificial bee colony algorithm [4] and variable neighborhood search algorithm [5]. In particular, it improves the best known results of 16 graphs in known literature algorithms.

The paper is organized as follows. Section 2 describes the related work of heuristic algorithms. Section 3 describes the general framework and the components of memetic algorithm, including the population initialization, the data splitting operation, the improved K-OPT local search procedure of individuals, the evolutionary operation and the disturbance operation. Section 4 describes the design process of simulated annealing algorithm. Section 5 describes the design process of greedy algorithm. Section 6 describes the experimental results. Section 7 describes the conclusion of the paper.

\section{Related Work}

In [6,7], the parameterized and approximation algorithms are proposed to solve the load coloring problem, and theoretically prove their capability in finding the best solution. On the other hand, considering the theoretical intractability of MLCP, several heuristic algorithms are proposed to find the best solutions. Heuristic algorithms use rules based on previous experience to solve a combinatorial optimization problem at the cost of acceptable time and space, and, at the same time, comparatively better results can be obtained. The heuristic algorithms used here include an artificial bee colony algorithm [4], a tabu search algorithm [5] and a variable neighborhood search algorithm [5] to solve MLCP.

Furthermore, to find the best solutions of the other combinatorial optimization problems, several heuristic algorithms are employed, such as a variable neighborhood search algorithm [8,9], a tabu search algorithm [10-13], a simulated annealing algorithm [14-17], and a greedy algorithm [18].

Local search algorithm, as an important heuristic algorithm, has been improved and evolved into many updated forms, such as a variable depth search algorithm [19], a reactive local search algorithm [20], an iterated local search algorithm [21], and a phased local search algorithm [22].

Memetic algorithm $[23,24]$ is an optimization algorithm which combines population-based global search and individual-based local heuristic search, whose application is found in solving combinatorial optimization problems. Memetic algorithm is also proposed to solve the minimum sum coloring problem of graphs [24].

\section{A Memetic Algorithm for MLCP}

In this paper, we propose an efficient memetic algorithm to solve MLCP of graphs. In our algorithm, there are several important design parts.

(1) Construct the population for the global search.

(2) Search heuristically the individuals to find better solutions.

(3) Evolve the population to find better solutions.

Memetic algorithm is summarized in Memetic_D_O_MLCP (Algorithm 1). After population initialization, the algorithm randomly generates a population $X$ consisting of $p$ individuals (Algorithm 1 , 
Line 2, Section 3.2). Then, the memetic algorithm repeats a series of generations (limited to a stop condition) to explore the search space defined by the set of all proper 2-colorings (Section 3.1). For each generation, by data splitting operation, the population $X$ is expanded to population $Z$ with twice as much as the data amount (Algorithm 1, Line 5, Section 3.3). An improved K- OPT local search is carried out for each individual $Z_{j}(0 \leq j<|Z|)$ of the population $Z$ to find the best solution of MLCP (Algorithm 1, Line 8, Section 3.4). If the improved solution has a better value, it is then used to update the best solution found so far (Algorithm 1, Lines 9-10). Finally, an evolutionary operation is conducted in population $Z$ to get a replaced one instead of population $X$ (Algorithm 1, Line 14, Section 3.5). To further improve the search ability of the algorithm and find better solutions, we add a disturbance operation into the memetic algorithm (Algorithm 1, Line 15, Section 3.6).

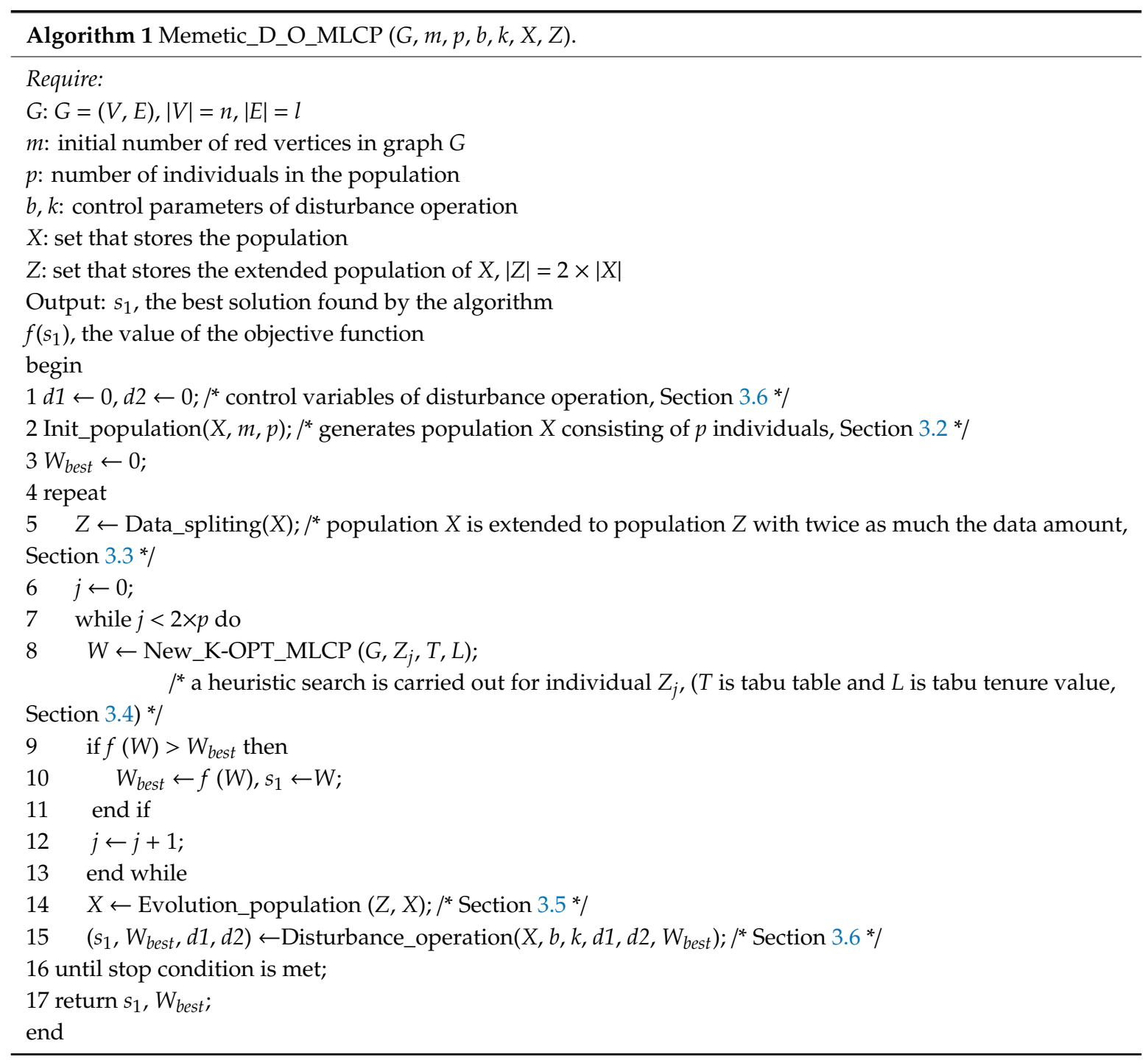

\subsection{Search Space and Objective Function}

In [1], the following description is considered to be MLCP's equivalent problem. A graph $G=(V$, $E$ ) is given, in which $V$ is a set of $n$ vertices, and $E$ is a set of $l$ edges. $\left(V_{\text {red }}, V_{\text {blue }}\right)$ is a two-color load coloring bipartition scheme of $V$, in which $V_{\text {red }}$ is the set of vertices which are red, and $V_{\text {blue }}$ is the set of vertices which are blue, here $V=V_{\text {red }} \cup V_{\text {blue }}$. The aim is to find the maximum value of $\min \left\{\left|\operatorname{Er}\left(V_{\text {red }}\right)\right|\right.$, $\left.\left|\operatorname{Er}\left(V_{\text {blue }}\right)\right|\right\}$ from all bipartition schemes of $\left(V_{\text {red }}, V_{\text {blue }}\right)$ such that $l_{q}$ can minimize. The maximum value is the minimum two-color load problem solution of graph $G$. Here, $\operatorname{Er}\left(V_{\text {red }}\right)$ is the set of edges with both end-points in $V_{\text {red }}$, and $\operatorname{Er}\left(V_{\text {blue }}\right)$ is the set of edges with both end-points in $V_{\text {blue }}$. 
The algorithm conducts a searching within the bipartition scheme $\left(V_{\text {red }}, V_{\text {blue }}\right)$, here $\left|V_{\text {red }}\right| \subset V$, $V_{\text {blue }}=V \backslash V_{\text {red }}$, when $\left|\operatorname{Er}\left(V_{\text {red }}\right)\right| \approx\left|\operatorname{Er}\left(V_{\text {blue }}\right)\right|,\left(V_{\text {red }}, V_{\text {blue }}\right)$ is the solution of the MLCP found by the algorithm. The search space $S$ of the algorithm is defined as follows:

$$
S=\left\{\left(V_{\text {red }}, V_{\text {blue }}\right)\left|V_{\text {red }} \subset V, V_{\text {blue }}=V \backslash V_{\text {red }}\right|\right\}
$$

The objective function is as follows:

$$
\left\{\begin{array}{l}
f\left(\left(V_{\text {red }}, V_{\text {blue }}\right)\right)=\min \left\{\left|\operatorname{Er}\left(V_{\text {red }}\right)\right|,\left|\operatorname{Er}\left(V_{\text {blue }}\right)\right|\right\} \\
\operatorname{Er}\left(V_{\text {red }}\right)=\left\{(v, w) \mid \forall(v, w) \in E, v \in V_{\text {red }}, w \in V_{\text {red }}\right\} \\
\operatorname{Er}\left(V_{\text {blue }}\right)=\left\{(v, w) \mid \forall(v, w) \in E, v \in V_{\text {blue }}, w \in V_{\text {blue }}\right\}
\end{array} .\right.
$$

We define the best solution of the MLCP as follows:

$$
f_{b}\left(\left(V_{\text {red }}, V_{\text {blue }}\right)\right)=\max _{1 \leq j \leq t}\left\{f\left(\left(V_{\text {red }}, V_{\text {blue }}\right)_{j}\right)\right\}
$$

Here, $t$ is the number of all solutions that can be found by the algorithm in graph $G$, and $\left(V_{\text {red }}\right.$, $\left.V_{b l u e}\right)_{j}$ is the $j$ th solution of the MLCP found by the algorithm.

Suppose a graph $G=(V, E)$ is given in Figure 1 . Let $|V|=6,|E|=8$, and then the best solution for MLCP of graph $G$ is shown in Figure 2, and its best value is 2 .

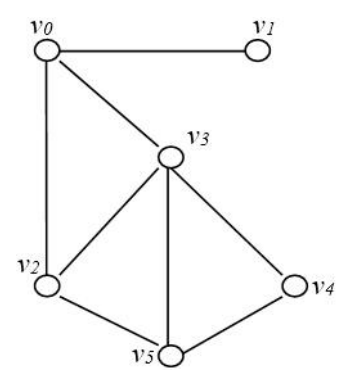

Figure 1. An instance of undirected graph G.

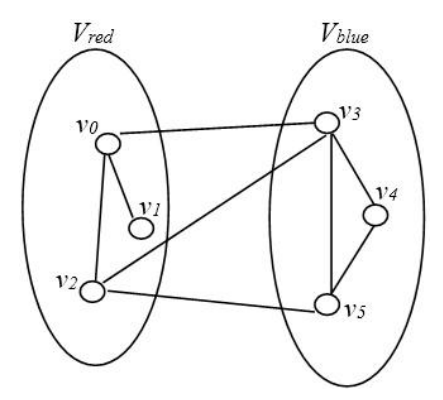

Figure 2. A best solution for MLCP of graph G.

\subsection{Initial Population}

The algorithm randomly generates population $X$ consisting of $p$ individuals. For the given graph $G=(V, E)$, in which $V$ is a set containing $n$ vertices, and $E$ is a set containing $l$ edges, $m$ vertices are chosen at random from $V$ to construct set $V_{\text {red }}$ ( $m$ is the initial number of the red vertices); and the remaining vertices are used to construct set $V_{\text {blue }}$, that is, $\left|V_{\text {red }}\right|=m, V_{\text {blue }}=V \backslash V_{\text {red }}$. Sets $V_{\text {red }}$ and $V_{\text {blue }}$ are seen as a bipartition scheme $\left(V_{\text {red }}, V_{\text {blue }}\right)$, which is also treated as an individual in population $X$. In this way, $p$ individuals are generated at random initially, and population $X$ is thus constructed, $|X|=p$. 


\subsection{Data Splitting Operation}

To avoid the defect of the local optima, we expand the data amount of population $X$, hence we get an expanded scope of data search. We use two data splitting strategies to split a bipartition scheme into two. Thus, by using the first data splitting strategy each individual $X_{i}(0 \leq i<p)$ in population $X$ generates an individual $Z_{2 \times i}$, and by using the second data splitting strategy each individual $X_{i}(0 \leq i<p)$ generates an individual $Z_{2 \times i+1}$. By doing this, $p$ individuals in population $X$ are divided into $2 \times p$ individuals, and the enlarged population $Z$ is constructed $(|X|=p,|Z|=2 \times p)$. Figure 3 shows the population expansion, where the red arrow indicates the effects of the first data splitting strategy and the blue arrow the effects of the second data splitting strategy.

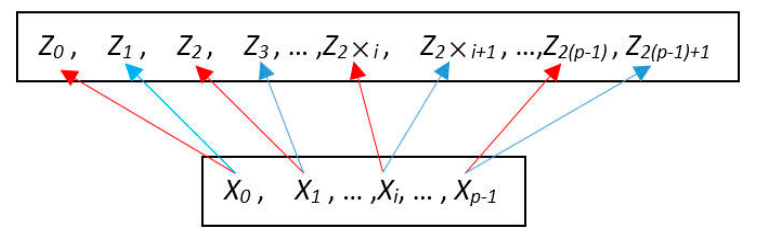

Figure 3. Expanding population $X$ to population $Z$.

The first data splitting strategy of bipartition scheme $\left(V_{\text {red }}, V_{\text {blue }}\right)$ is an important part of memetic algorithm, which consists of five steps.

First step: Degree set Degree $_{\text {red }}$ of all vertices in sub-graph $G_{1}\left(V_{\text {red }}\right)$ is calculated.

Second step: Find the minimum degree vertex, $v$, from Degree $_{\text {red }}$. If there is more than one vertex with the same minimum degree, randomly select a vertex among them.

Third step: Degree set Degree blue of all vertices in sub-graph $G_{2}\left(V_{\text {blue }}\right)$ is calculated.

Fourth step: Find the minimum degree vertex, $w$, from Degree blue. If there is more than one vertex with the same minimum degree, randomly select a vertex among them.

Fifth step: A new bipartition scheme $\left(V^{\prime}{ }_{r e d}, V^{\prime}{ }_{\text {blue }}\right)$ is generated by exchanging the vertices $v$ and $w$ in sets $V_{\text {red }}$ and $V_{\text {blue }}$.

Suppose the number of red vertices is 4 in the given graph $G=(V, E), V=\left\{v_{0}, v_{1}, \ldots, v_{9}\right\}$. We obtain a bipartition scheme $\left(V_{\text {red }}, V_{\text {blue }}\right)$, as shown in Figure $4 \mathrm{a}$, in which set $V_{\text {red }}=\left\{v_{0}, v_{3}, v_{8}, v_{9}\right\}$, $V_{\text {blue }}=\left\{v_{1}, v_{2}, v_{4}, v_{5}, v_{6}, v_{7}\right\}$, where the degree of vertex $v_{9}$ in set $V_{\text {red }}$ is the smallest, and that of vertex $v_{4}$ in set $V_{\text {blue }}$ is the smallest. After exchanging the two vertices, a new bipartition scheme $\left(V^{\prime}{ }^{\prime}\right.$ ed, $\left.V^{\prime}{ }_{\text {blue }}\right)$ is generated. The new bipartition scheme $\left(V^{\prime}{ }_{\text {red }}, V^{\prime}{ }_{\text {blue }}\right)$ after splitting is: $V^{\prime}{ }_{\text {red }}=\left\{v_{0}, v_{3}, v_{4}, v_{8}\right\}$, $V_{\text {blue }}^{\prime}=\left\{v_{1}, v_{2}, v_{5}, v_{6}, v_{7}, v_{9}\right\}$, as shown in Figure $4 \mathrm{~b}$.

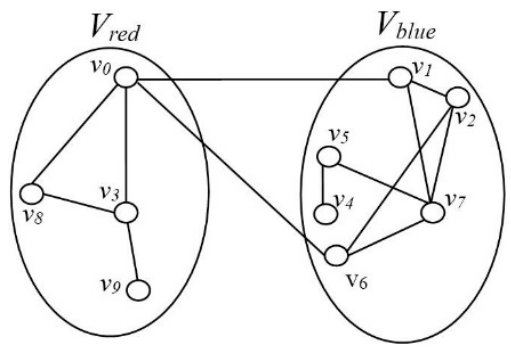

(a)

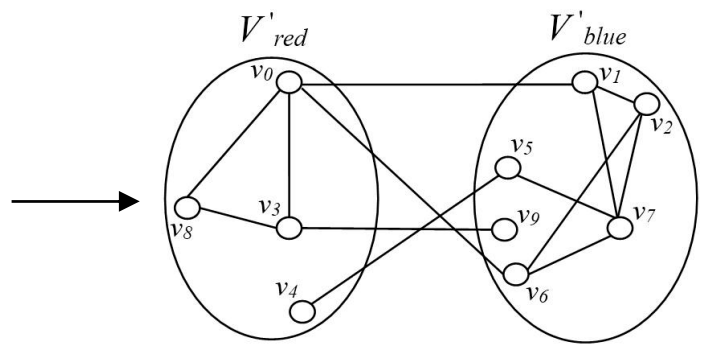

(b)

Figure 4. Bipartition scheme splitting: (a) bipartition scheme before the splitting; and (b) bipartition scheme after the splitting.

The second data splitting strategy is described as follows: for a given bipartition scheme $\left(V_{\text {red }}\right.$, $\left.V_{\text {blue }}\right)$, in which $\left|V_{\text {red }}\right|=m, V_{\text {blue }}=V \backslash V_{\text {red }}$, randomly a vertex $v$ in set $V_{\text {red }}$ is chosen, and a vertex $w$ in set $V_{\text {blue }}$ is randomly chosen. Then, vertices $v$ and $w$ in set $V_{\text {red }}$ and set $V_{\text {blue }}$ are exchanged to generate a new bipartition scheme $\left(V^{\prime \prime}{ }_{\text {red }}, V^{\prime \prime}\right.$ blue $)$. 


\subsection{Search for the Individuals}

Memetic algorithm needs to carry out a heuristic search for each individual in the population by an effective and improved K-OPT local search algorithm designed.

We first obtain an individual $Z_{j}$ which is a $\left(V_{\text {red }}, V_{\text {blue }}\right)_{j},\left(\left(V_{\text {red }}\right)_{j} \subset V,\left(V_{\text {blue }}\right)_{j}=V \backslash\left(V_{\text {red }}\right)_{j}, 0 \leq j<|Z|\right)$. The local search algorithm is implemented to add as many selected vertices, acquired through our vertex adding strategy, as possible in set $\left(V_{b l u e}\right)_{j}$ to set $\left(V_{r e d}\right)_{j}$, until the stop condition set by the algorithm is met. Thus, a new bipartition scheme $\left(V_{\text {red }}, V_{\text {blue }}\right)^{\prime}{ }_{j}$ is constructed. Generally speaking, in $\left(V_{\text {red }}, V_{\text {blue }}\right)^{\prime}{ }^{\prime},\left|\operatorname{Er}\left(\left(V^{\prime}{ }_{r e d}\right)_{j}\right)\right|$ is approximately equal to $\mid \operatorname{Er}\left(\left(V^{\prime}{ }^{\prime} \text { lue }\right)_{j}\right) \mid$. Then, the objective function value $f$ $\left(\left(V_{\text {red }}, V_{\text {blue }}\right)_{j}^{\prime}\right)$ is calculated using Equation (2). If $f\left(\left(V_{\text {red }}, V_{\text {blue }}\right)^{\prime}{ }^{\prime}\right)>f\left(s_{1}\right)$, the memetic algorithm accepts the constructed bipartition as the new best solution. The improved K-OPT local search algorithm is implemented by the New_K-OPT_MLCP (Algorithm 2).

Our vertex adding strategy is described as follows:

We first need to define the following three vectors as the foundation on which the vertex adding strategy is constructed.

- $\quad C C_{\text {red }}$ : The current set of red vertices in graph $G$.

- $P A V_{\text {red }}$ : The vertex set of possible additions, i.e., each vertex is connected to at least one vertex of $C C_{\text {red }}$.

$$
P A V_{\text {red }}=\left\{v \mid v \in V_{\text {blue }}, \exists w \in C C_{\text {red }},(v, w) \in E, V_{\text {blue }}=V \backslash C C_{\text {red }}\right\} .
$$

- $G P A V_{\text {red }}$ : The degree set of vertices $v_{i} \in P A V_{\text {red }}$ in sub-graph $G^{\prime}\left(P A V_{\text {red }}\right)$, where $P A V_{\text {red }} \subseteq V_{\text {blue }}$.

$$
\left\{\begin{array}{l}
G P A V_{\text {red }}[i]=\text { degree }_{G^{\prime}\left(P A V_{\text {red }}\right)}\left(v_{i}\right)=\left|\left\{a \mid \forall a \in P A V_{\text {red }}\left(v_{i}, a\right) \in E\right\}\right| \\
v_{i} \in P A V_{\text {red }} \\
0 \leq i \leq\left|P A V_{\text {red }}\right|-1
\end{array} .\right.
$$

To avoid the local optima defect, the vertex adding strategy is employed in two phases: vertex addition phase (Algorithm 2, Lines 8-12) and vertex deletion phase (Algorithm 2, Lines 14-18).

In the vertex addition phase of $C C_{\text {red }}$, we obtain $P A V_{\text {red }}$ from the current $C C_{\text {red }}$, then select a vertex $w$ from $P A V_{\text {red }}$ and move it from $V_{\text {blue }}$ to $C C_{\text {red }}$, and finally update $P A V_{\text {red }}$. The vertex addition phase is repeatedly executed until $P A V_{\text {red }}=\varnothing$ or $\left|\operatorname{Er}\left(C C_{\text {red }}\right)\right|>\left|\operatorname{Er}\left(V_{\text {blue }}\right)\right|$.

In the vertex deletion phase of $C C_{r e d}$, we select a vertex $u$ from $C C_{r e d}$, then delete the vertex $u$ from $C C_{r e d}$, and add it to $V_{\text {blue }}$. Go back to the vertex addition phase again to continue the execution until the set ending conditions are met.

The approach to select vertex $w$ is first to obtain a $G P A V_{\text {red }}$ in sub-graph $G^{\prime}\left(P A V_{\text {red }}\right)$, then to calculate the vertex selection probability value $\rho\left(w_{i}\right)$ of each vertex $w_{i}\left(0 \leq i<\left|P A V_{\text {red }}\right|\right)$ in $P A V_{\text {red }}$, and finally to select vertex $w_{i}$ to maximize $\rho\left(w_{i}\right)$. If there are more than one vertex with the maximum value of $\rho\left(w_{i}\right)$, randomly select one.

$$
\left\{\begin{array}{l}
\operatorname{maxd}=\max _{w_{i} \in P A V_{\text {red }}, 0 \leq i<\left|P A V_{\text {red }}\right|}\left(\text { degree }_{G^{\prime}\left(\text { PAV }_{\text {red }}\right)}\left(w_{i}\right)\right) \\
\rho\left(w_{i}\right)=\frac{\operatorname{maxd}+1-G P A V_{\text {red }}[\mathrm{i}]}{\operatorname{maxd}+1} \\
w_{i} \in P A V_{\text {red }} \\
0 \leq i<\left|P A V_{\text {red }}\right|
\end{array} .\right.
$$

A vertex $w$ is selected according to the following criterion:

$$
f_{1}(w)=\max _{0 \leq i<\left|P A V_{\text {red }}\right|}\left(\rho\left(w_{i}\right)\right) .
$$

We found that the larger the probability value $\rho\left(w_{i}\right)$ of vertex $w_{i}$ is, the smaller the degree value of vertex $w_{i}$ becomes. 
The approach of vertex $u$ selection is as follows: we assume that $\left(C C_{\text {red }}, V_{b l u e}\right)^{(j)}$ is the bipartition scheme with no possible additions. We successively take the value of $i$ from the range of $0-\left(\left|C C_{\text {red }}\right|\right.$ - 1), and then in turn execute $C C_{\text {red }}(j) \backslash\left\{u_{i}\right\}$ as follows: delete vertex $u_{i}$ from $C C_{\text {red }}{ }^{(j)}$ successively to generate new bipartition schemes $\left(C C^{\prime}{ }_{\text {red }}, V^{\prime}{ }_{\text {blue }}\right)_{i}$, i.e., $\left.\left(C C^{\prime}{ }_{\text {red }}\right)_{i} \leftarrow C C_{\text {red }}{ }^{(j)} \backslash\left\{u_{i}\right\},\left(V^{\prime}{ }_{\text {blue }}\right)_{i} \leftarrow V_{\text {blue }}\right)^{(j)} \cup\left\{u_{i}\right\}$, $u_{i} \in C C_{r e d}, 0 \leq i<\left|C C_{r e d}\right|$, and finally obtain $E d\left(\left(C C^{\prime}{ }_{r e d}, V^{\prime}{ }_{\text {blue }}\right)_{i}\right)$.

$$
\left\{\begin{array}{l}
E d\left(\left(C C_{\text {red }}^{\prime}, V_{\text {blue }}^{\prime}\right)_{i}\right)=\left|\left\{(x, y) \mid \forall(x, y) \in E, x \in\left(C C_{\text {red }}^{\prime}\right)_{i}, y \in\left(V_{\text {blue }}^{\prime}\right)_{i}\right\}\right| \\
\left(V_{\text {blue }}^{\prime}\right)_{i}=V \backslash\left(C C_{\text {red }}^{\prime}\right)_{i} \\
0 \leq i<\left|C C_{\text {red }}(j)\right|
\end{array} .\right.
$$

The maximum value maxdd is found from all the values of $E d$, and the vertex selection probability value $\rho_{2}\left(u_{i}\right)$ of vertex $u_{i}$ can be calculated:

$$
\left\{\begin{array}{l}
\max d d=\max _{0 \leq i<\left|C C_{\text {red }}(j)\right|}\left(E d\left(\left(C C_{\text {red }}^{\prime}, V_{\text {blue }}^{\prime}\right)_{i}\right)\right) \\
\rho_{2}\left(u_{i}\right)=\frac{{\operatorname{maxdd}+1-E d\left(\left(C C_{\text {red }}^{\prime}, V_{\text {blue }}^{\prime}\right)_{i}\right)}_{\max d d+1}}{u_{i} \in C C_{\text {red }}(j)} \\
0 \leq i<\left|C C_{\text {red }}(j)\right|
\end{array}\right.
$$

A vertex $u$ is selected according to the following criterion:

$$
f_{2}(u)=\max _{u_{i} \in C C_{\text {red }}(j), 0 \leq i<\left|C C_{\text {red }}(j)\right|}\left(\rho_{2}\left(u_{i}\right)\right) .
$$

We found that the larger the probability value $\rho_{2}\left(u_{i}\right)$ of vertex $u_{i}$ is, the smaller the corresponding $E d\left(\left(C C^{\prime} \text { red, } V^{\prime} \text { blue }\right)_{i}\right)$ becomes. If there are more than one vertices with the maximum value of $\rho_{2}\left(u_{i}\right)$, randomly select one.

At each generation, the variable $g A$ stores the value of vertices number successfully added to the $C C_{\text {red }}$ for now, and the variable gmaxA stores the value of vertices number successfully added to the $C C_{\text {red }}$ during the previous generations. If $g A>\operatorname{gmax} A$, the incumbent $C C_{\text {red }}$ has more red vertices than the previous ones found by the local search algorithm. Then, gmaxA is updated with the value of $g A$ and the incumbent $C C_{\text {red }}$ is stored to the set Abest (Algorithm 2, Line 12). In the vertex addition phase, the value of $g A+1$ replaces that of $g A(g A \leftarrow g A+1)$ after a vertex is added. In the vertex deletion phase, the value of $g A-1$ replaces that of $g A(g A \leftarrow g A-1)$ after a vertex is deleted.

At the completion of the inner loop statements, when gmax $A>0, C C_{\text {red }}$, which has the greatest number of vertices, is stored in set Abest, then the incumbent $C C_{\text {red }}$ is updated with Abest. When $\operatorname{gmax} A=0, C C_{\text {red }}$, which has the greatest number of vertices, is stored in set Aprev; if the execution of the inner loop does not find any new set $C C_{\text {red }}$ that has more vertices, Aprev is adopted as $C C_{\text {red }}$ generated by the previous execution of the inner loop and will replace the incumbent $\mathrm{CC}_{\text {red }}$ (Algorithm 2, Lines 22-28).

The algorithm's search efficiency may be reduced because of the roundabout searching characteristics. To solve this problem, a restricting tabu table is added to the local search algorithm.

The tabu table can be presented by two-dimensional array or one-dimensional array. We adopt the one-dimensional array $T$, set the tabu tenure value as $L$, and store the iteration numbers of running the local search algorithm into the tabu table. When the algorithm runs reach iteration value $c$, and if $(c-T[w])<L$ or if $(c-T[u])<L$, it means vertex $w$ or $u$ has been processed and the vertex should be re-selected. Otherwise, the current value $c$ is stored in the tabu table, i.e., $T[w] \leftarrow c$ or $T[u] \leftarrow c$. 


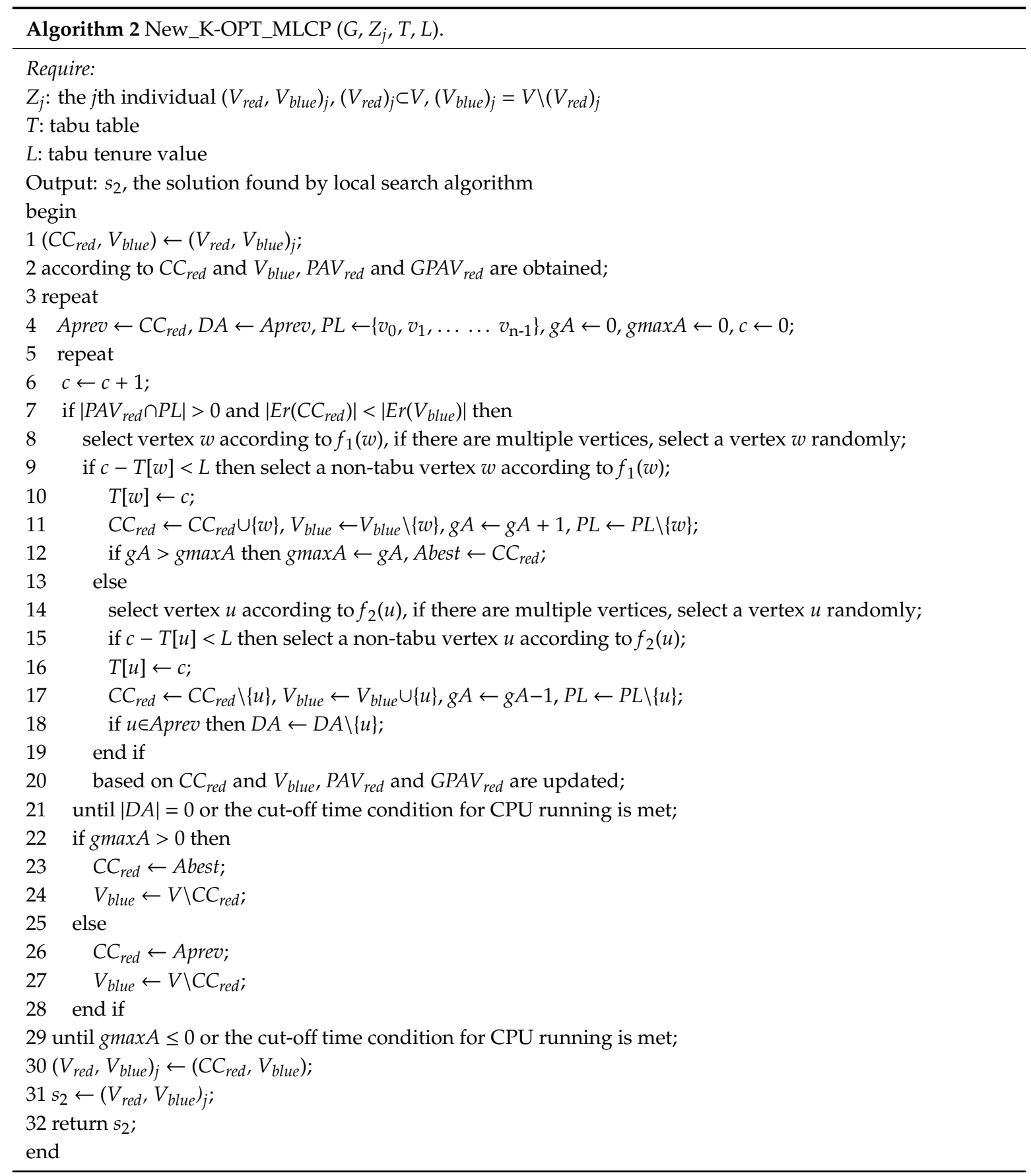

\subsection{Evolutionary Operation of Population}

An evolutionary operation in the population $X$ is needed to quickly find the best solution of MLCP. We sort the individuals $Z_{j}(0 \leq j<2 \times p)$ in population $Z$ in ascending order according to the calculated value of objective function $f_{*}$ in Equation (11). Then, we replace the individuals $X_{0}-X_{p-1}$ of population $X$ with the individuals $Z_{0}-Z_{p-1}$ to complete the evolutionary operation.

$$
f_{*}\left(\left(V_{\text {red }}, V_{\text {blue }}\right)_{j}\right)=\left|\left\{(a, b) \mid \forall(a, b) \in E, a \in\left(V_{\text {red }}\right)_{j}, b \in\left(V_{\text {blue }}\right)_{j}\right\}\right|, 0 \leq j<2 \times p .
$$

Evolution operation of the population is represented by Evolution_population (Algorithm 3). 


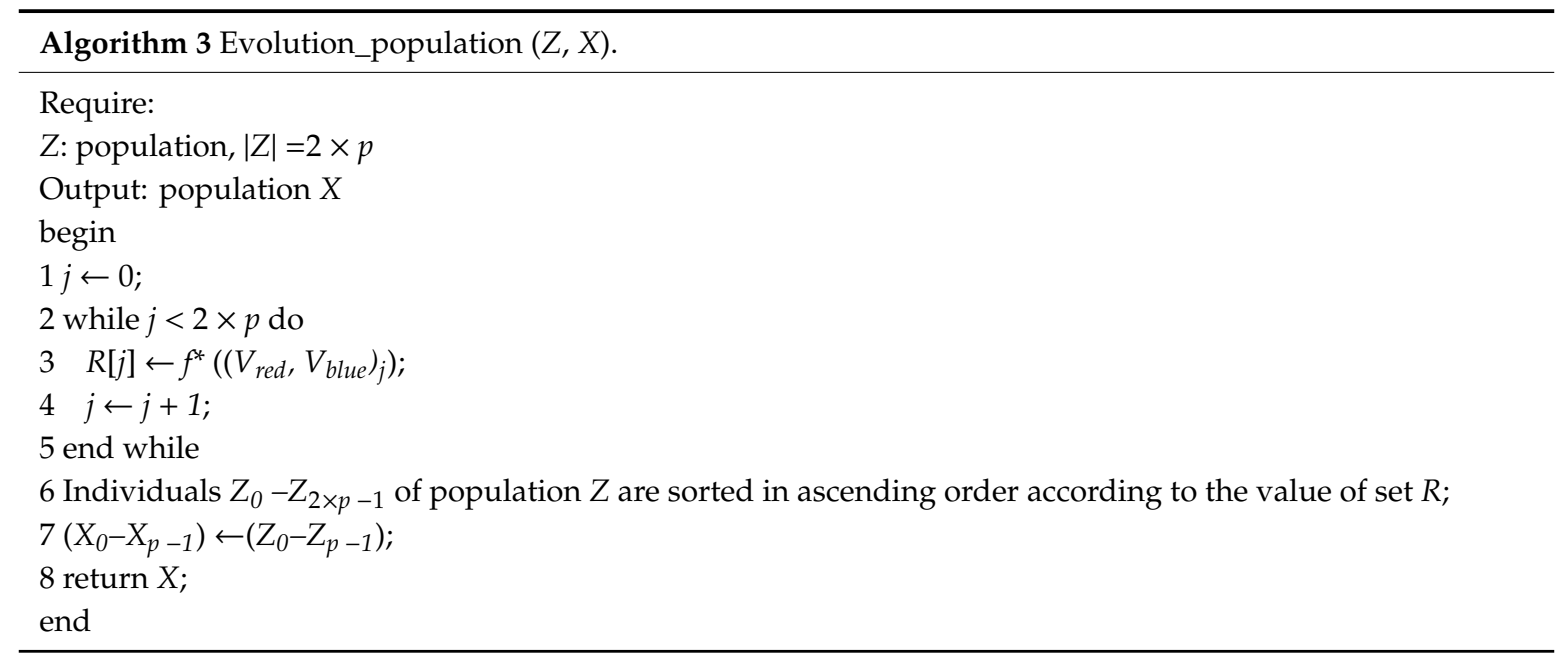

\subsection{Disturbance Operation}

To further improve the search ability of the algorithm and find better values, we add a disturbance operation into the memetic algorithm. This disturbance operation is executed $k$ times.

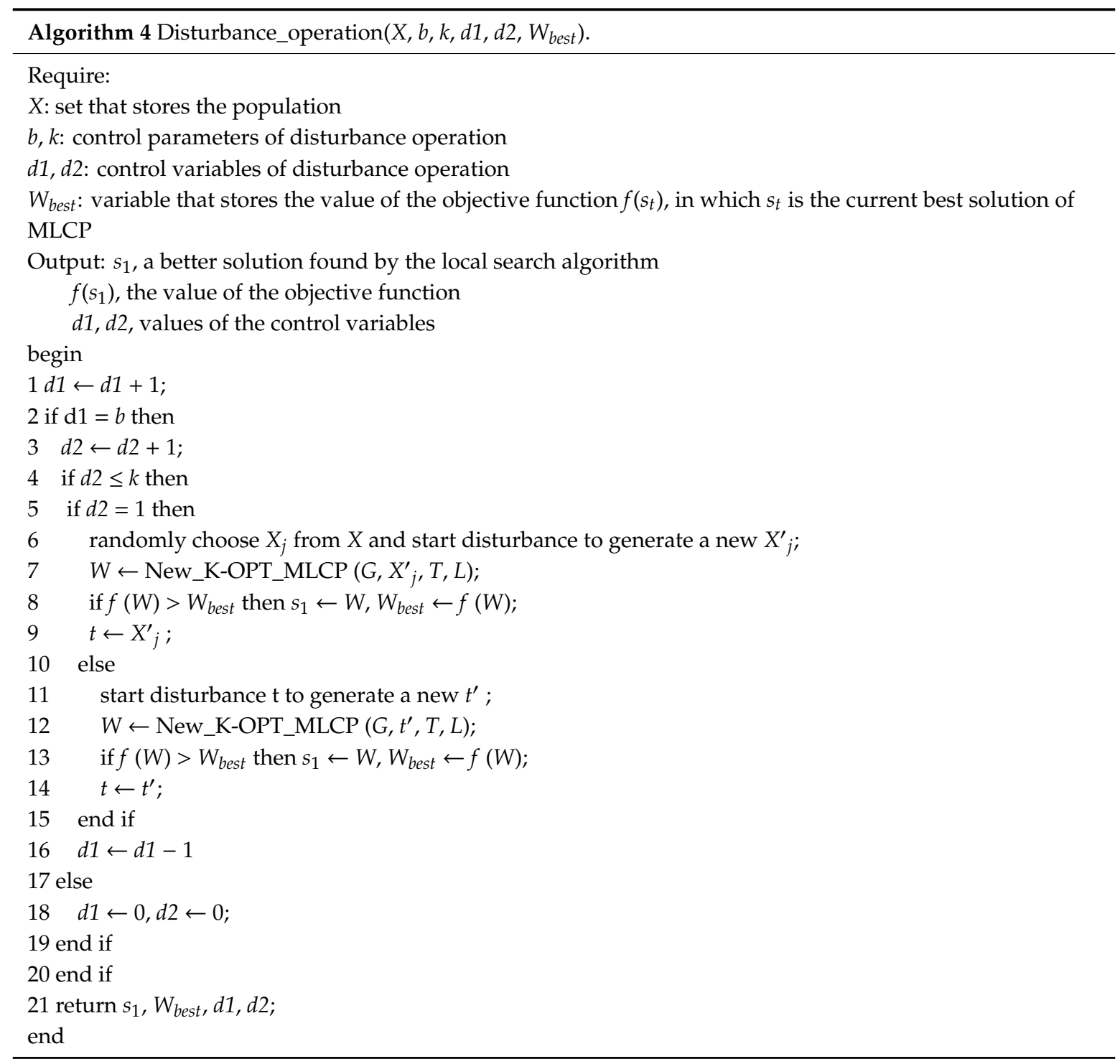


When the number of iterations is $b$, disturbance operation begins and randomly selects an individual $\left(V_{\text {red }}, V_{\text {blue }}\right)_{j}(0 \leq j<|X|)$ from population $X$, and chooses at random a vertex from set $V_{\text {red }}$ and a vertex from set $V_{\text {blue }}$, then the two vertices are exchanged to generate a new $\left(V_{\text {red }}, V_{\text {blue }}\right)^{\prime}$. Then, employ the New_K-OPT_MLCP algorithm to search in $\left(V_{\text {red }}, V_{\text {blue }}\right)^{\prime}$; if a better solution of MLCP is found, the memetic algorithm will accept it.

The disturbance operation is represented by Disturbance_operation (Algorithm 4).

In Memetic_D_O_MLCP algorithm, setting the value of $b$ and $k$ will determine the disturbance operation's starting condition and the number of times of its execution. In Disturbance_operation algorithm, Lines $1,3,16$, and 18 store the modified values of variables $d 1$ and $d 2$, which are the threshold values needed to start off a new disturbance operation.

\section{Simulated Annealing Algorithm}

Simulated annealing algorithm, a classical heuristic algorithm to solve combinatorial optimization problems, starts off from a higher initial temperature. With the decreasing of temperature parameters, the algorithm can randomly find the global best solution of problems instead of the local optima by combining the perturbations triggered by the probabilities.

For a given graph $G$, simulated annealing algorithm finds a coloring bipartition scheme ( $V_{\text {red }}$, $V_{\text {blue }}$ ) of $V$ which maximizes $\min \left\{\left|\operatorname{Er}\left(V_{\text {red }}\right)\right|, \mid \operatorname{Er}\left(V_{\text {blue }}\right)\right\}$. With parameters $T_{0}$ (initial temperature value), $\alpha$ (cooling coefficient) and $T_{\text {end }}$ (the end temperature value), first, the algorithm divides the vertex set $V$ into two sets, i.e., $V_{\text {red }}$ and $V_{\text {blue }}\left(V_{\text {red }}=\varnothing, V_{\text {blue }}=V\right)$ and the initial value of the best solution of MLCP $C_{\text {best }}$ is set to 0 . Next, a vertex is randomly selected in $V_{\text {blue }}$ and moved from $V_{\text {blue }}$ to $V_{\text {red }}$; here, $\left|V_{\text {red }}\right|=1, V_{\text {blue }}=V \backslash V_{\text {red }}$. Then, the algorithm repeats a series of generations to explore the search space defined by the set of all 2-colorings. At each generation, a vertex is randomly selected in $V_{\text {blue }}$ and moved from $V_{\text {blue }}$ to $V_{\text {red }}$. The additions will take place in the following three forms:

When $2>\left|V_{\text {red }}\right|$ and $2 \leq\left|V_{\text {blue }}\right|$, a vertex is randomly selected in $V_{\text {blue }}$ and moved from $V_{\text {blue }}$ to $V_{\text {red }}$ to generate a new coloring bipartition scheme $\left(V^{\prime}{ }_{\text {red }}, V^{\prime}\right.$ blue $)$ and the new status is accepted.

When $2>\left|V_{\text {blue }}\right|$ and $2 \leq\left|V_{\text {red }}\right|$, a vertex is randomly selected in $V_{\text {red }}$ and moved from $V_{\text {red }}$ to $V_{\text {blue }}$ to generate a new coloring bipartition scheme $\left(V^{\prime}{ }_{\text {red }}, V^{\prime}{ }_{\text {blue }}\right)$ and accepted as the new status.

When $2 \leq\left|V_{\text {red }}\right|$ and $2 \leq\left|V_{\text {blue }}\right|$, a vertex is randomly selected from $V_{\text {red }}$ and one randomly from $V_{\text {blue }}$, then the two vertices are exchanged to generate a new coloring bipartition scheme $\left(V^{\prime}{ }_{\text {red }}, V^{\prime}\right.$ blue $)$, only when $R_{1}\left(\left(V^{\prime}{ }_{\text {red }}, V^{\prime}{ }_{\text {blue }}\right)\right) \geq R_{1}\left(\left(V_{\text {red }}, V_{\text {blue }}\right)\right)$, the scheme is accepted as a new status. Otherwise, the probability will decide whether to accept it as a new status or not.

Once the new status is accepted, if $C_{\text {best }}<R_{1}\left(\left(V^{\prime}\right.\right.$ red,$V^{\prime}$ blue $\left.)\right)$, then the bipartition scheme $\left(V^{\prime}\right.$ red, $V^{\prime}{ }_{\text {blue }}$ ) is accepted as the best solution of MLCP.

At the end of each generation, the temperature $T$ cools down until $T \leq T_{\text {end }}$ according to $T=T \times \alpha$, where $\alpha \in(0,1)$. The algorithm runs iteratively as per the above steps until the stop condition is met.

The best solution found by the algorithm is $R_{b}\left(\left(V_{\text {red }}, V_{\text {blue }}\right)\right)$, i.e.,

$$
\left\{\begin{array}{l}
R_{1}\left(\left(V_{\text {red }}, V_{\text {blue }}\right)_{j}\right)=\min \left\{\left|\operatorname{Er}\left(\left(V_{\text {red }}\right)_{j}\right)\right|,\left|\operatorname{Er}\left(\left(V_{\text {blue }}\right)_{j}\right)\right|\right\} \\
R_{b}\left(\left(V_{\text {red }}, V_{\text {blue }}\right)\right)=\max _{0 \leq j<t}\left\{R_{1}\left(\left(V_{\text {red }}, V_{\text {blue }}\right)_{j}\right)\right\}
\end{array} .\right.
$$

Here, $t$ is the number of all solutions that can be found by the simulated annealing algorithm in graph $G$, and $\left(V_{\text {red }}, V_{b l u e}\right)_{j}$ is the $j$ th solution of MLCP.

The simulated annealing algorithm is represented by SA (Algorithm 5). 


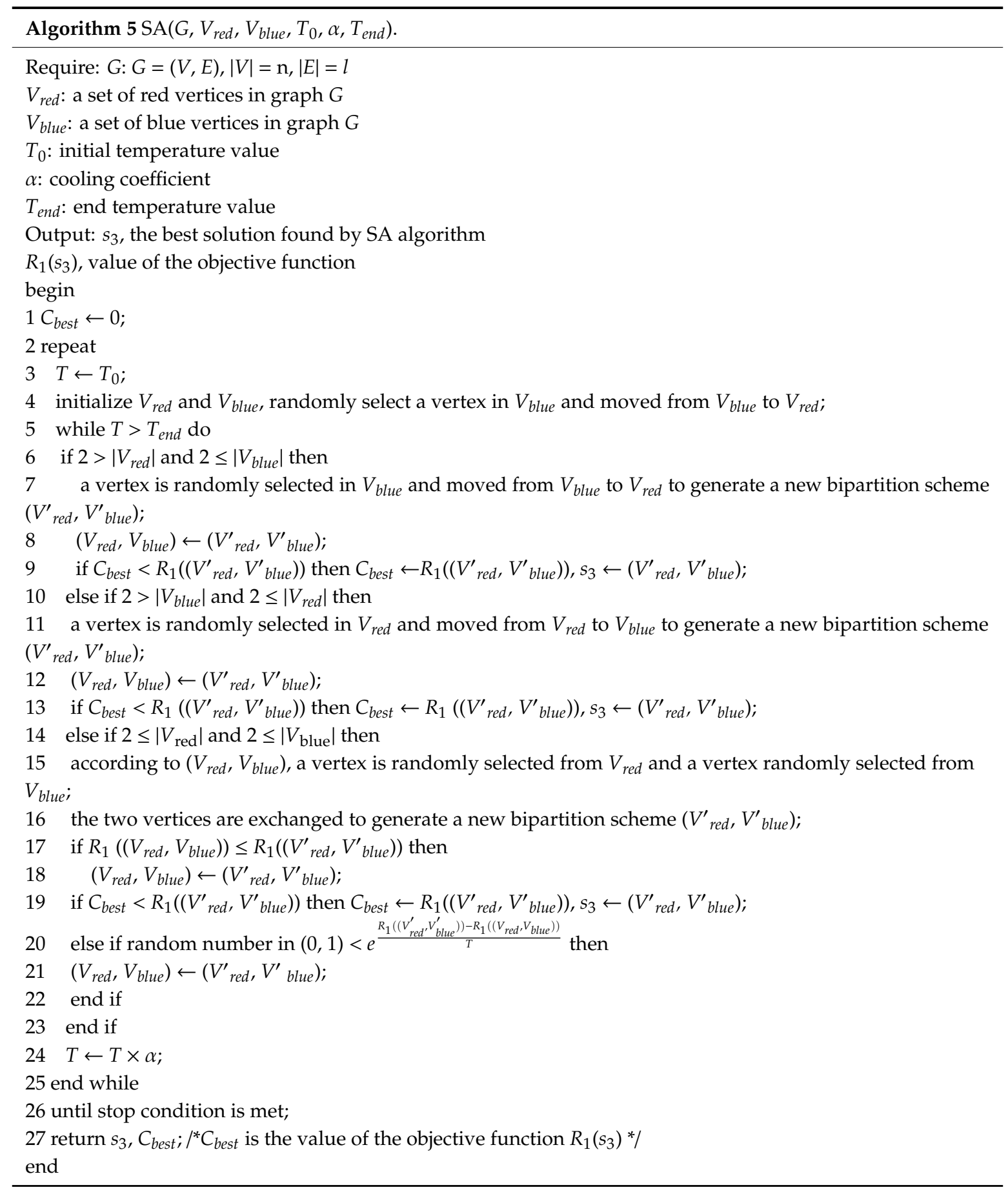

\section{Greedy Algorithm}

Greedy algorithm aims at making the optimal choice at each stage with the hope of finding a global best solution. For a given graph $G$, greedy algorithm finds a coloring bipartition scheme $\left(V_{\text {red }}\right.$, $\left.V_{\text {blue }}\right)$ of $V$ which maximizes $\min \left\{\left|\operatorname{Er}\left(V_{\text {red }}\right)\right|,\left|\operatorname{Er}\left(V_{\text {blue }}\right)\right|\right\}$.

When a graph $G=(V, E)$ is given, the algorithm divides vertex set $V$ into two sets, i.e., $V_{\text {red }}$ and $V_{\text {blue }}\left(V_{\text {red }}=\varnothing, V_{\text {blue }}=V\right)$, and the initial value of the best solution of MLCP $C_{\text {best }}$ is set to 0 . Next, a vertex is randomly selected in $V_{\text {blue }}$ and moved from $V_{\text {blue }}$ to $V_{\text {red }}$, here $\left|V_{\text {red }}\right|=1, V_{\text {blue }}=V \backslash V_{\text {red }}$. Then, the algorithm repeats a series of generations to explore the search space defined by the set of all 2-colorings. At each generation, based on sub-graph $G^{\prime}\left(V_{\text {blue }}\right)$, choose a vertex $w$ of the minimum degree $\left(w \in V_{\text {blue }}\right)$; if there are more than one vertex with the same minimum degree, randomly select a 
vertex among them. Then, add the vertex from $V_{\text {blue }}$ to $V_{\text {red }}$, that is: $V_{\text {red }} \leftarrow V_{\text {red }} \cup\{w\}, V_{\text {blue }} \leftarrow V_{\text {blue }} \backslash\{w\}$, thus a new bipartition scheme $\left(V^{\prime}{ }_{\text {red }}, V^{\prime}{ }_{\text {blue }}\right)$ is generated, and, when $R_{2}\left(\left(V^{\prime}{ }_{\text {red }}, V^{\prime}{ }_{\text {blue }}\right)\right)>C_{\text {best }}$, the scheme is accepted as the best solution. The generation will be repeated until $\left|\operatorname{Er}\left(V_{\text {red }}\right)\right|>\left|\operatorname{Er}\left(V_{\text {blue }}\right)\right|$.

The algorithm runs iteratively as per the above steps until the stop condition is met.

The best solution found by the algorithm is $R_{g}\left(\left(V_{\text {red }}, V_{\text {blue }}\right)\right)$, i.e.,

$$
\left\{\begin{array}{l}
R_{2}\left(\left(V_{\text {red }}, V_{\text {blue }}\right)_{j}\right)=\min \left\{\left|\operatorname{Er}\left(\left(V_{\text {red }}\right)_{j}\right)\right|,\left|\operatorname{Er}\left(\left(V_{\text {blue }}\right)_{j}\right)\right|\right\} \\
R_{g}\left(\left(V_{\text {red }}, V_{\text {blue }}\right)\right)=\max _{0 \leq j<t}\left\{R_{2}\left(\left(V_{\text {red }}, V_{\text {blue }}\right)_{j}\right)\right\}
\end{array} .\right.
$$

Here, $t$ is the number of all solutions that can be found by the greedy algorithm in graph $G$, and $\left(V_{\text {red }}, V_{b l u e}\right)_{j}$ is the $j$ th solution of MLCP.

The greedy algorithm is represented by Greedy (Algorithm 6).

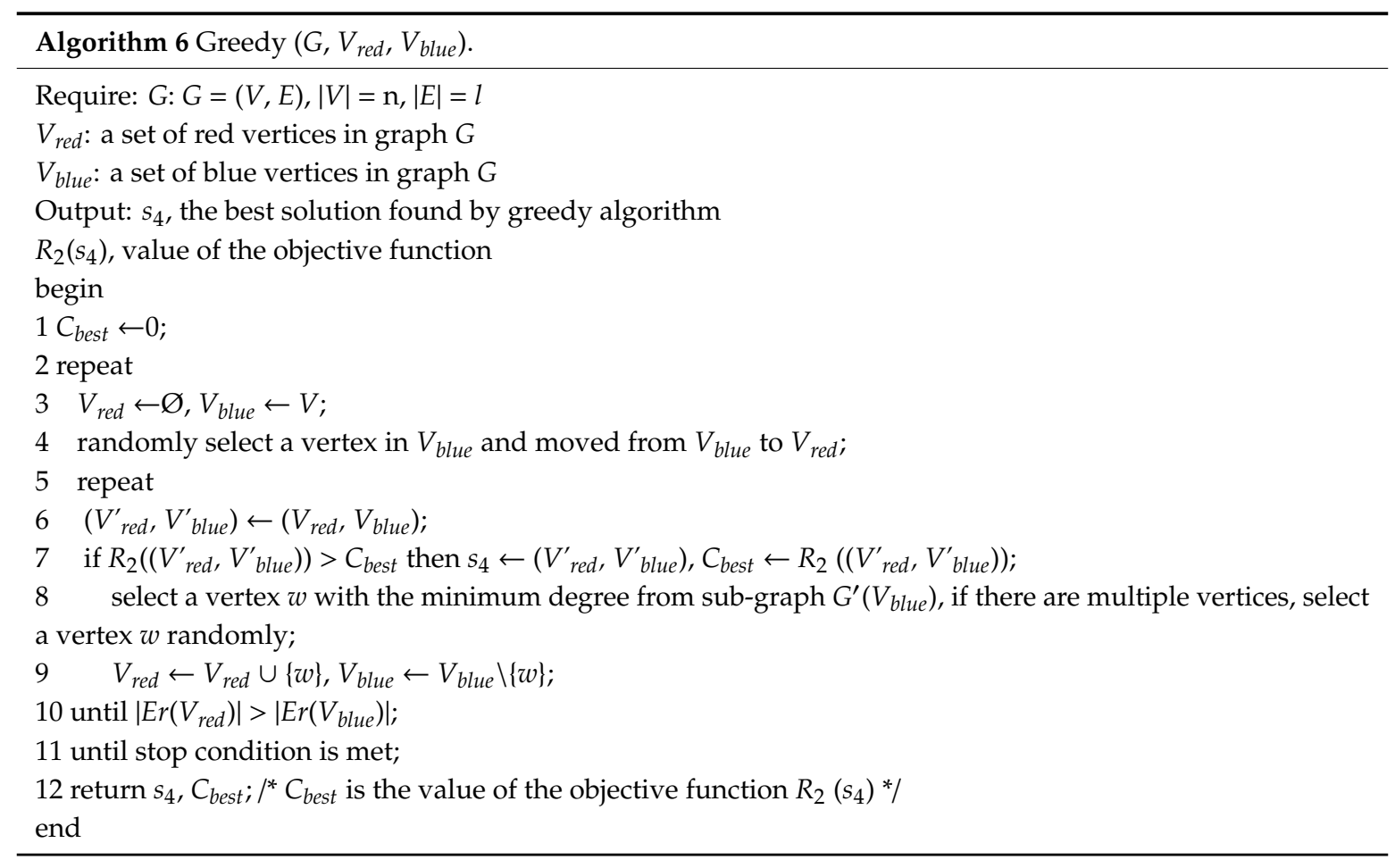

\section{Experimental Results}

All algorithms were programmed in $\mathrm{C}++$, and run on a PC with Intel Pentium(R) G630 processor 2.70 GHz and $4 \mathrm{~GB}$ memory under Windows 7 (64 bits), and the test graphs adopted were the benchmark DIMACS proposed in [5]. We compared the search results by using memetic algorithm, simulated annealing algorithm, and greedy algorithm. Then, the results of memetic algorithm were compared with those obtained from using artificial bee colony algorithm [4], tabu search algorithm [5] and variable neighborhood search algorithm [5].

The first group of experiments was performed to adjust the key parameters and analyze their influence on Memetic_D_O_MLCP. As is known to all, the most important parameters in Memetic_D_O_MLCP implementations are the values of $p$ and $L$, which determine the number of the individuals of the population and the tabu tenure value during the search process. To find the most suitable values of $p$ and $L$ for Memetic_D_O_MLCP approach to MLCP, we performed experiments with different values of $p$ and L. Memetic_D_O_MLCP was run 10 times for each benchmark instance, and each test lasted $30 \mathrm{~min}$.

The results of experiments are summarized in Table 1, organized as follows: in the first column, Inst the benchmark instance name is given, containing the vertices set $V$; and, in the second column, 
$m$ is the initial number of red vertices in the benchmark graph. For each $p \in\{4,12,20\}$ and $L \in\{10,60,90\}$, column Best contains the best values of MLCP solution found by the algorithm, while column Avg represents the average values of MLCP solution found by the algorithm. For each instance, the best values of Best and Avg are shown in italics. The analysis of the obtained results shows that values of $p$ and $L$ influence the solution quality. For example, the number of best values of Best is 5 for combination $p=12$ and $L=90$; Best 3 for $p=4, L=90$ and $p=20, L=60$; Best 2 for $p=4$ and $L=10, p=4$ and $L=60, p=12$ and $L=60$; Best 1 for $p=20$ and $L=90$; Best 0 for $p=12$ and $L=10, p=20$ and $L=10$. Meanwhile, the number of best values of $A v g$ is 2 for combinations $p=12$ and $L=90, p=4$ and $L=90$; Avg 1 for $p=4$ and $L=10, p=4$ and $L=60, p=12$ and $L=60, p=20$ and $L=10, p=20$ and $L=60$, $p=20$ and $L=90$.

In Table 1 , one observes that, for combination $p=12$ and $L=90$, the number of instances where the Memetic_D_O_MLCP achieved the best value for Best and Avg is 5 and 2, respectively. For all other combinations, these numbers are the biggest. Therefore, we used the combination in all other experiments.

The second groups of tests compared the search results of Memetic_D_O_MLCP, SA algorithm and Greedy algorithm, each having been run 20 times for each benchmark instance with the cut-off time of $30 \mathrm{~min}$. In simulated annealing algorithm, the initial temperature $T_{0}$ is set at 1000, the cooling coefficient $\alpha$ at 0.9999 and the end temperature $T_{\text {end }}$ at 0.0001 . The results of experiments are summarized in Table 2 , organized as follows: in the second column, $|V|$ is the number of vertices; and, in the third column, $|E|$ is the number of edges. For each instance the best values of Best are shown in italics. Among 59 instances, the search results of Memetic_D_O_MLCP, SA algorithm and Greedy algorithm were the same in the instances myciel3.col, myciel4.col, queen5_5.col and queen6_6.col. Memetic_D_O_MLCP and Greedy algorithm could find equivalent best value of four instances (i.e., queen7_7.col, queen8_8.col, queen8_12.col, and queen9_9.col). In the remaining 51 instances, Memetic_D_O_MLCP could find the best results of 38 instances (accounting for 75\%), and Greedy algorithm could find the best results of 13 instances (accounting for $25 \%$ ). The experiments showed that Memetic_D_O_MLCP could find more instances of best values.

The third group of tests aimed at comparing the search results after each algorithm was run on four benchmark instances, namely myciel6.col, homer.col, mulsol.i.5.col and inithx.i.1.col, for the first one $100 \mathrm{~s}$. The results that algorithms found were collected at an interval of $10 \mathrm{~s}$. The running time was regarded as the $X$ coordinate on the axis and the value of MLCP solution as the $Y$ coordinate.

Figure 5 illustrates that Memetic_D_O_MLCP can find the best result at each time node. 
Table 1. Experiments with parameters $p$ and $L$.

\begin{tabular}{|c|c|c|c|c|c|c|c|c|c|c|c|c|c|c|c|c|c|c|c|}
\hline \multirow{3}{*}{ Inst } & \multirow{3}{*}{$m$} & \multicolumn{6}{|c|}{$p=4$} & \multicolumn{6}{|c|}{$p=12$} & \multicolumn{6}{|c|}{$p=20$} \\
\hline & & \multicolumn{2}{|c|}{$L=10$} & \multicolumn{2}{|c|}{$L=60$} & \multicolumn{2}{|c|}{$L=90$} & \multicolumn{2}{|c|}{$L=10$} & \multicolumn{2}{|c|}{$L=60$} & \multicolumn{2}{|c|}{$L=90$} & \multicolumn{2}{|c|}{$L=10$} & \multicolumn{2}{|c|}{$L=60$} & \multicolumn{2}{|c|}{$L=90$} \\
\hline & & Best & $A v g$ & Best & $A v g$ & Best & $A v g$ & Best & $A v g$ & Best & $A v g$ & Best & $A v g$ & Best & $A v g$ & Best & $A v g$ & Best & $A v g$ \\
\hline fpsol2.i.1.col & $|V| / 5$ & 3035 & 2844 & 3033 & 2857 & 3582 & 2928 & 3015 & 2840 & 3002 & 2845 & 3029 & 2837 & 3071 & 2929 & 2942 & 2727 & 2998 & 2843 \\
\hline fpsol2.i.2.col & $|V| / 5$ & 2120 & 1965 & 2375 & 1953 & 2183 & 1860 & 2272 & 1972 & 2176 & 1944 & 2450 & 1969 & 2324 & 2016 & 2169 & 1932 & 2310 & 2038 \\
\hline fpsol2.i.3.col & $|V| / 5$ & 2141 & 1930 & 2331 & 1931 & 2266 & 2048 & 2333 & 1960 & 2330 & 1930 & 2115 & 1900 & 1981 & 1817 & 2397 & 1986 & 2281 & 1951 \\
\hline DSJC125.1.col & $|V| / 5$ & 255 & 252 & 254 & 252 & 254 & 251 & 254 & 252 & 255 & 252 & 255 & 252 & 254 & 252 & 255 & 253 & 254 & 252 \\
\hline DSJC125.5.col & $|V| / 5$ & 1081 & 1072 & 1082 & 1067 & 1088 & 1078 & 1084 & 1076 & 1087 & 1080 & 1089 & 1080 & 1084 & 1078 & 1087 & 1072 & 1084 & 1074 \\
\hline queen15_15.col & $|V| / 5$ & 1716 & 1699 & 1721 & 1678 & 1721 & 1694 & 1693 & 1650 & 1705 & 1692 & 1716 & 1681 & 1659 & 1632 & 1704 & 1638 & 1674 & 1641 \\
\hline mulsol.i.4.col & $|V| / 5$ & 1704 & 1694 & 1704 & 1698 & 1704 & 1694 & 1701 & 1695 & 1704 & 1696 & 1704 & 1698 & 1700 & 1697 & 1704 & 1697 & 1704 & 1694 \\
\hline
\end{tabular}


Table 2. Test results of the Memetic_D_O_MLCP, SA, and Greedy on benchmark instances.

\begin{tabular}{|c|c|c|c|c|c|c|c|c|c|}
\hline \multirow{2}{*}{ Inst } & \multirow{2}{*}{$|V|$} & \multirow{2}{*}{$|E|$} & \multicolumn{3}{|c|}{ Memetic_D_O_MLCP } & \multicolumn{2}{|c|}{ SA } & \multicolumn{2}{|c|}{ Greedy } \\
\hline & & & $m$ & Best & $\operatorname{Avg}$ & Best & $A v g$ & Best & $A v g$ \\
\hline anna.col & 138 & 986 & $|\mathrm{~V}| / 5$ & 200 & 198 & 160 & 154 & 131 & 131 \\
\hline david.col & 87 & 812 & $|\mathrm{~V}| / 5$ & 158 & 157 & 133 & 130 & 140 & 140 \\
\hline DSJC125.1.col & 125 & 736 & $|\mathrm{~V}| / 5$ & 255 & 252 & 222 & 217 & 240 & 238 \\
\hline DSJC125.5.col & 125 & 3891 & $|\mathrm{~V}| / 5$ & 1091 & 1083 & 1025 & 1021 & 1075 & 1067 \\
\hline DSJC125.9.col & 125 & 6961 & $|\mathrm{~V}| / 5$ & 1798 & 1789 & 1761 & 1756 & 1776 & 1772 \\
\hline fpsol2.i.1.col & 496 & 11654 & $|\mathrm{~V}| / 5$ & 3091 & 2896 & 3016 & 2982 & 2510 & 2502 \\
\hline fpsol2.i.2.col & 451 & 8691 & $|\mathrm{~V}| / 5$ & 2290 & 2046 & 2267 & 2242 & 1707 & 1703 \\
\hline fpsol2.i.3.col & 425 & 8688 & $|\mathrm{~V}| / 5$ & 2387 & 1996 & 2291 & 2247 & 1664 & 1664 \\
\hline games120.col & 120 & 1276 & $|\mathrm{~V}| / 5$ & 288 & 281 & 215 & 209 & 284 & 284 \\
\hline homer.col & 561 & 3258 & 10 & 662 & 655 & 450 & 441 & 492 & 489 \\
\hline huck.col & 74 & 602 & $|\mathrm{~V}| / 5$ & 130 & 129 & 111 & 109 & 113 & 113 \\
\hline inithx.i.1.col & 864 & 18707 & 10 & 6644 & 6153 & 4861 & 4773 & 6167 & 6050 \\
\hline inithx.i.2.col & 645 & 13979 & 10 & 5622 & 5104 & 3641 & 3597 & 3571 & 3481 \\
\hline inithx.i.3.col & 621 & 13969 & 10 & 5589 & 4756 & 3643 & 3593 & 3131 & 3111 \\
\hline jean.col & 80 & 508 & $|\mathrm{~V}| / 5$ & 111 & 110 & 98 & 95 & 106 & 106 \\
\hline latin_square_10.col & 900 & 307350 & 10 & 85161 & 85072 & 77006 & 75770 & 85185 & 85185 \\
\hline le450_5a.col & 450 & 5714 & 10 & 1824 & 1801 & 1516 & 1495 & 1834 & 1827 \\
\hline le450_5b.col & 450 & 5734 & 10 & 1820 & 1801 & 1512 & 1498 & 1843 & 1831 \\
\hline le450_5c.col & 450 & 9803 & 10 & 2985 & 2951 & 2541 & 2530 & 3014 & 2995 \\
\hline le450_5d.col & 450 & 9757 & 10 & 2943 & 2913 & 2542 & 2519 & 2972 & 2958 \\
\hline le450_15b.col & 450 & 8169 & 10 & 2395 & 2355 & 2138 & 2120 & 2409 & 2398 \\
\hline le450_15c.col & 450 & 16680 & 10 & 4530 & 4476 & 4294 & 4267 & 4560 & 4539 \\
\hline le450_15d.col & 450 & 16750 & 10 & 4586 & 4542 & 4320 & 4289 & 4626 & 4609 \\
\hline le450_25a.col & 450 & 8260 & 10 & 2467 & 2434 & 2183 & 2148 & 2466 & 2454 \\
\hline le450_25b.col & 450 & 8263 & 10 & 2664 & 2606 & 2172 & 2149 & 2682 & 2658 \\
\hline le450_25c.col & 450 & 17343 & 10 & 4711 & 4652 & 4457 & 4438 & 4728 & 4714 \\
\hline le450_25d.col & 450 & 17425 & 10 & 4872 & 4807 & 4470 & 4449 & 4883 & 4875 \\
\hline miles250.col & 128 & 774 & $|\mathrm{~V}| / 5$ & 185 & 184 & 145 & 137 & 183 & 183 \\
\hline miles500.col & 128 & 2340 & $|\mathrm{~V}| / 5$ & 522 & 522 & 393 & 381 & 518 & 518 \\
\hline miles750.col & 128 & 4226 & $|\mathrm{~V}| / 5$ & 870 & 870 & 673 & 638 & 849 & 849 \\
\hline miles1000.col & 128 & 6432 & $|\mathrm{~V}| / 5$ & 1183 & 1180 & 954 & 921 & 1156 & 1156 \\
\hline miles1500.col & 128 & 10396 & $|\mathrm{~V}| / 5$ & 1645 & 1616 & 1461 & 1421 & 1485 & 1484 \\
\hline mulsol.i.1.col & 197 & 3925 & $|\mathrm{~V}| / 5$ & 1697 & 1690 & 1193 & 1152 & 1624 & 1624 \\
\hline mulsol.i.2.col & 188 & 3885 & $|\mathrm{~V}| / 5$ & 1685 & 1682 & 1153 & 1117 & 1202 & 1189 \\
\hline mulsol.i.3.col & 184 & 3916 & $|\mathrm{~V}| / 5$ & 1695 & 1692 & 1174 & 1131 & 1211 & 1174 \\
\hline mulsol.i.4.col & 185 & 2946 & $|\mathrm{~V}| / 5$ & 1704 & 1701 & 1172 & 1134 & 1218 & 1195 \\
\hline mulsol.i.5.col & 186 & 3973 & $|\mathrm{~V}| / 5$ & 1714 & 1713 & 1189 & 1144 & 1216 & 1210 \\
\hline myciel3.col & 11 & 20 & $|\mathrm{~V}| / 5$ & 5 & 5 & 5 & 5 & 5 & 5 \\
\hline myciel4.col & 23 & 71 & $|\mathrm{~V}| / 5$ & 21 & 21 & 21 & 21 & 21 & 21 \\
\hline myciel6.col & 95 & 755 & $|\mathrm{~V}| / 5$ & 233 & 231 & 215 & 212 & 194 & 193 \\
\hline myciel7.col & 191 & 2360 & $|\mathrm{~V}| / 5$ & 723 & 717 & 643 & 634 & 574 & 574 \\
\hline queen5_5.col & 25 & 320 & $|\mathrm{~V}| / 5$ & 46 & 46 & 46 & 46 & 46 & 46 \\
\hline queen6_6.col & 36 & 580 & $|\mathrm{~V}| / 5$ & 91 & 91 & 91 & 88 & 91 & 91 \\
\hline queen7_7.col & 49 & 952 & $|\mathrm{~V}| / 5$ & 148 & 147 & 145 & 141 & 148 & 148 \\
\hline queen8_8.col & 64 & 1456 & $|\mathrm{~V}| / 5$ & 236 & 232 & 219 & 214 & 236 & 228 \\
\hline queen8_12.col & 96 & 2736 & $|\mathrm{~V}| / 5$ & 458 & 453 & 400 & 391 & 458 & 458 \\
\hline queen9_9.col & 81 & 2112 & $|\mathrm{~V}| / 5$ & 340 & 336 & 308 & 304 & 340 & 334 \\
\hline queen10_10.col & 100 & 2940 & $|\mathrm{~V}| / 5$ & 485 & 479 & 419 & 415 & 468 & 466 \\
\hline queen11_11.col & 121 & 3960 & $|\mathrm{~V}| / 5$ & 644 & 643 & 563 & 556 & 633 & 633 \\
\hline queen12_12.col & 144 & 5192 & $|\mathrm{~V}| / 5$ & 866 & 853 & 725 & 717 & 833 & 833 \\
\hline queen13_13.col & 169 & 6656 & $|\mathrm{~V}| / 5$ & 1097 & 1093 & 918 & 909 & 1067 & 1067 \\
\hline queen14_14.col & 196 & 8372 & $|\mathrm{~V}| / 5$ & 1407 & 1385 & 1148 & 1131 & 1346 & 1345 \\
\hline queen15_15.col & 225 & 10360 & $|\mathrm{~V}| / 5$ & 1721 & 1706 & 1402 & 1376 & 1676 & 1675 \\
\hline queen16_16.col & 256 & 12640 & $|\mathrm{~V}| / 5$ & 2107 & 2075 & 1668 & 1652 & 2051 & 2048 \\
\hline school1.col & 385 & 19095 & 10 & 6633 & 6553 & 4951 & 4886 & 6644 & 6644 \\
\hline school1_nsh.col & 352 & 14612 & 10 & 5545 & 5450 & 3838 & 3780 & 5548 & 5548 \\
\hline zeroin.i.1.col & 211 & 4100 & 10 & 1210 & 1198 & 1113 & 1095 & 924 & 923 \\
\hline zeroin.i.2.col & 211 & 3541 & 10 & 1135 & 1126 & 975 & 959 & 803 & 800 \\
\hline zeroin.i.3.col & 206 & 3540 & 10 & 1134 & 1126 & 981 & 964 & 800 & 799 \\
\hline
\end{tabular}




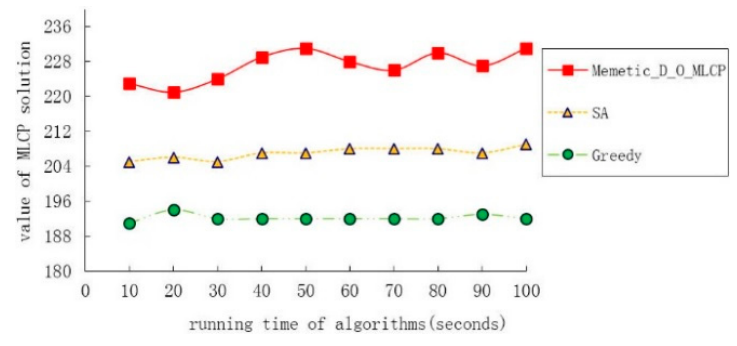

(a) myciel6.col

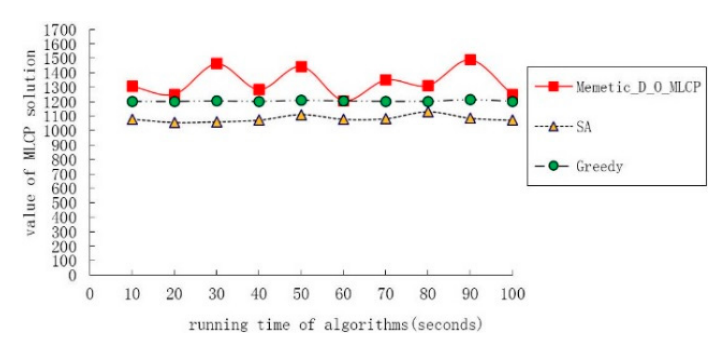

(c) mulsol.i.5.col

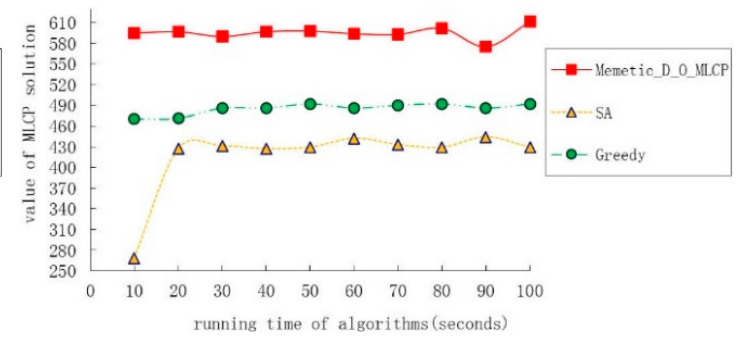

(b) homer.col

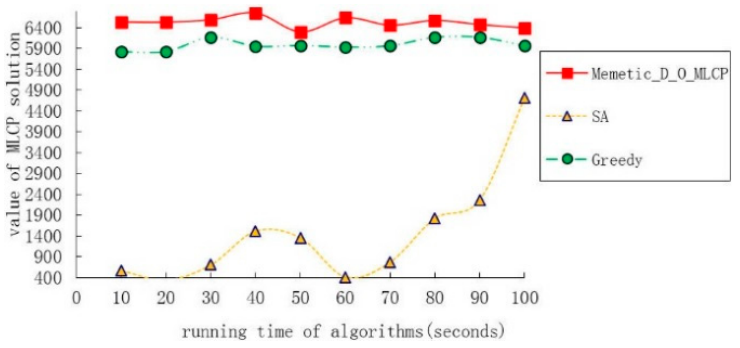

(d) inithx.i.1.col

Figure 5. Running curves of the Memetic_D_O_MLCP, SA and Greedy on benchmark instances.

The fourth group of tests compared the time each algorithm took to find the best results, each being run 20 times for 32 instances with the cut-off time of $30 \mathrm{~min}$.

The results are summarized in Table 3. Compared with SA algorithm and Greedy algorithm, it took less time for Memetic_D_O_MLCP to find the best results for the 11 instances (shown in italics). Accounting for $34 \%$ in the total, these 11 instances were: fpsol2.i.2.col, huck.col, mulsol.i.3.col, mulsol.i.4.col, mulsol.i.5.col,myciel6.col,queen10_10.col,queen11_11.col,queen15_15.col,inithx.i.3.col, and zeroin.i.2.col. For six instances, namely david.col, DSJC125.9.col, games120.col, miles250.col, miles750.col, and jean.col, which accounted for $19 \%$ in the total, the time spent by Memetic_D_O_MLCP and Greedy algorithm showed little difference. Additionally, the former found better results than the latter. For the remaining 15 instances, although the time taken by Memetic_D_O_MLCP was longer than that by Greedy algorithm, as it consumed more time for executing the operations of data splitting, searching, evolution and disturbance, the results found by the former were better than those by the latter. Of all 32 instances, comparing with Memetic_D_O_MLCP, SA algorithm spent more time to find the best results; besides, the Best $\mathrm{SA}$ algorithm results were inferior.

The comparison between Memetic_D_O_MLCP and artificial bee colony (ABC) algorithm [4] is summarized in Table 4. For each instance, the best values of Best are shown in italics. Of all 21 instances proposed in [4], except that the search results of instances myciel3.col and myciel4.col were equivalent to that of artificial bee colony algorithm, Memetic_D_O_MLCP found better results (accounting for 90\%) and improved the best-known result of instance myciel5.col. 
Table 3. Running time of the Memetic_D_O_MLCP, SA and Greedy on benchmark instances.

\begin{tabular}{|c|c|c|c|c|c|c|c|c|c|c|}
\hline \multirow{2}{*}{ Inst } & \multicolumn{4}{|c|}{ Memetic_D_O_MLCP } & \multicolumn{3}{|c|}{ SA } & \multicolumn{3}{|c|}{ Greedy } \\
\hline & $m$ & Best & $A v g$ & Time(min) & Best & $A v g$ & Time(min) & Best & $A v g$ & Time(min) \\
\hline anna.col & $|\mathrm{V}| / 5$ & 200 & 199 & 5.30 & 159 & 150 & 17.29 & 131 & 131 & 0.09 \\
\hline david.col & $|\mathrm{V}| / 5$ & 158 & 157 & 0.47 & 140 & 130 & 21.97 & 140 & 140 & 0.02 \\
\hline DSJC125.1.col & $|\mathrm{V}| / 5$ & 254 & 252 & 27.92 & 220 & 214 & 29.76 & 239 & 237 & 19.24 \\
\hline DSJC125.5.col & $|\mathrm{V}| / 5$ & 1086 & 1078 & 22.82 & 1026 & 1012 & 28.20 & 1075 & 1067 & 14.07 \\
\hline DSJC125.9.col & $|\mathrm{V}| / 5$ & 1797 & 1785 & 18.86 & 1757 & 1752 & 14.04 & 1782 & 1773 & 17.81 \\
\hline fpsol2.i.1.col & $|\mathrm{V}| / 5$ & 3073 & 2871 & 23.52 & 2984 & 2966 & 13.42 & 2510 & 2504 & 4.78 \\
\hline fpsol2.i.2.col & $|\mathrm{V}| / 5$ & 2274 & 1882 & 17.20 & 2250 & 2226 & 25.58 & 1707 & 1706 & 22.30 \\
\hline games120.col & $|\mathrm{V}| / 5$ & 288 & 280 & 1.05 & 216 & 205 & 29.74 & 284 & 284 & 0.05 \\
\hline huck.col & $|\mathrm{V}| / 5$ & 130 & 129 & 0.03 & 113 & 109 & 6.86 & 113 & 113 & 0.09 \\
\hline miles250.col & $|\mathrm{V}| / 5$ & 185 & 184 & 5.92 & 140 & 134 & 29.67 & 183 & 183 & 4.05 \\
\hline miles500.col & $|\mathrm{V}| / 5$ & 522 & 522 & 1.11 & 389 & 375 & 25.71 & 518 & 518 & $<0.01$ \\
\hline miles750.col & $|\mathrm{V}| / 5$ & 870 & 870 & 1.72 & 644 & 618 & 17.17 & 849 & 849 & 0.07 \\
\hline miles1000.col & $|\mathrm{V}| / 5$ & 1186 & 1178 & 18.53 & 938 & 892 & 24.83 & 1156 & 1156 & 0.22 \\
\hline miles1500.col & $|\mathrm{V}| / 5$ & 1619 & 1613 & 27.56 & 1453 & 1411 & 15.90 & 1485 & 1485 & 2.36 \\
\hline mulsol.i.1.col & $|\mathrm{V}| / 5$ & 1695 & 1689 & 20.94 & 1164 & 1089 & 28.06 & 1624 & 1624 & 0.29 \\
\hline mulsol.i.2.col & $|\mathrm{V}| / 5$ & 1685 & 1680 & 26.63 & 1157 & 1065 & 22.97 & 1202 & 1188 & 8.10 \\
\hline mulsol.i.3.col & $|\mathrm{V}| / 5$ & 1693 & 1687 & 22.76 & 1147 & 1112 & 23.56 & 1209 & 1183 & 25.14 \\
\hline mulsol.i.4.col & $|\mathrm{V}| / 5$ & 1704 & 1694 & 25.22 & 1139 & 1091 & 29.25 & 1218 & 1186 & 28.08 \\
\hline mulsol.i.5.col & $|\mathrm{V}| / 5$ & 1714 & 1705 & 23.77 & 1165 & 1093 & 20.23 & 1214 & 1207 & 28.68 \\
\hline jean.col & $|\mathrm{V}| / 5$ & 111 & 110 & 0.13 & 97 & 93 & 18.93 & 106 & 106 & 0.02 \\
\hline myciel6.col & $|\mathrm{V}| / 5$ & 232 & 231 & 20.01 & 213 & 211 & 19.19 & 194 & 192 & 26.07 \\
\hline myciel7.col & $|\mathrm{V}| / 5$ & 719 & 710 & 18.73 & 631 & 624 & 27.23 & 574 & 574 & 3.68 \\
\hline queen10_10.col & $|\mathrm{V}| / 5$ & 485 & 478 & 1.42 & 418 & 410 & 10.08 & 468 & 466 & 21.61 \\
\hline queen11_11.col & $|\mathrm{V}| / 5$ & 644 & 643 & 2.56 & 554 & 539 & 21.94 & 640 & 633 & 12.95 \\
\hline queen12_12.col & $|\mathrm{V}| / 5$ & 866 & 853 & 5.32 & 721 & 703 & 22.64 & 833 & 833 & 0.07 \\
\hline queen13_13.col & $|\mathrm{V}| / 5$ & 1097 & 1093 & 25.21 & 907 & 884 & 21.66 & 1067 & 1067 & 2.98 \\
\hline queen15_15.col & $|\mathrm{V}| / 5$ & 1697 & 1675 & 21.65 & 1377 & 1357 & 29.27 & 1676 & 1675 & 26.07 \\
\hline inithx.i.1.col & 10 & 6622 & 5982 & 23.36 & 4774 & 4696 & 11.55 & 6169 & 6044 & 1.45 \\
\hline inithx.i.3.col & 10 & 5362 & 4123 & 22.89 & 3616 & 3569 & 9.58 & 3151 & 3117 & 22.93 \\
\hline zeroin.i.1.col & 10 & 1207 & 1189 & 12.76 & 1111 & 1083 & 19.77 & 924 & 923 & 5.78 \\
\hline zeroin.i.2.col & 10 & 1131 & 1124 & 18.46 & 967 & 939 & 21.43 & 802 & 799 & 26.64 \\
\hline zeroin.i.3.col & 10 & 1131 & 1125 & 28.96 & 959 & 937 & 28.32 & 800 & 798 & 10.53 \\
\hline
\end{tabular}

Table 4. Comparison results on Memetic_D_O_MLCP and ABC.

\begin{tabular}{cccc}
\hline \multirow{2}{*}{ Inst } & \multicolumn{2}{c}{ Memetic_D_O_MLCP } & ABC \\
\cline { 2 - 4 } & $\boldsymbol{m}$ & Best & Best \\
\hline DSJC125.1.col & $|\mathrm{V}| / 5$ & 255 & 209 \\
DSJC125.5.col & $|\mathrm{V}| / 5$ & 1091 & 1005 \\
DSJC125.9.col & $|\mathrm{V}| / 5$ & 1798 & 1746 \\
fpsol2.i.1.col & $|\mathrm{V}| / 5$ & 3091 & 2956 \\
fpsol2.i.2.col & $|\mathrm{V}| / 5$ & 2290 & 2231 \\
fpsol2.i.3.col & $|\mathrm{V}| / 5$ & 2387 & 2207 \\
inithx.i.1.col & 10 & 6644 & 1295 \\
inithx.i.2.col & 10 & 5622 & 3574 \\
inithx.i.3.col & 10 & 5589 & 3548 \\
myciel3.col & $|\mathrm{V}| / 5$ & 5 & 5 \\
myciel4.col & $|\mathrm{V}| / 5$ & 21 & 21 \\
myciel5.col & $|\mathrm{V}| / 5$ & 73 & 68 \\
myciel6.col & $|\mathrm{V}| / 5$ & 233 & 207 \\
myciel7.col & $|\mathrm{V}| / 5$ & 723 & 621 \\
le450_5a.col & 10 & 1824 & 1475 \\
le450_5b.col & 10 & 1820 & 1490 \\
le450_5c.col & 10 & 2985 & 2505 \\
le450_5d.col & 10 & 2943 & 2493 \\
le450_15b.col & 10 & 2395 & 2110 \\
le450_15c.col & 10 & 4530 & 4217 \\
le450_15d.col & 10 & 4586 & 4227 \\
\hline
\end{tabular}

Furthermore, we compared the search results from Memetic_D_O_MLCP, tabu search (Tabu) algorithm [5] and variable neighborhood search (VNS) algorithm [5]; the results are shown in Table 5 
(the algorithms in the literature were run 20 times, each lasting $30 \mathrm{~min}$ for each benchmark instance). Memetic_D_O_MLCP could find the best results of 26 instances (shown in italics), in which the best results of 11 instances equaled those found by Tabu algorithm. Hence, Memetic_D_O_MLCP could improve the best-known results of the remaining 15 instances. Besides, of the 53 instances in Table 5, the best results of 22 instances found by Memetic_D_O_MLCP were better than those by Tabu algorithm, and the best results of 42 instances found by Memetic_D_O_MLCP were better than that of VNS algorithm.

Table 5. Comparison results on Memetic_D_O_MLCP, Tabu and VNS.

\begin{tabular}{|c|c|c|c|c|c|c|c|}
\hline \multirow{2}{*}{ Inst } & \multicolumn{3}{|c|}{ Memetic_D_O_MLCP } & \multicolumn{2}{|c|}{ Tabu } & \multicolumn{2}{|c|}{ VNS } \\
\hline & $m$ & Best & $A v g$ & Best & $A v g$ & Best & $A v g$ \\
\hline anna.col & $|\mathrm{V}| / 5$ & 200 & 198 & 195 & 182 & 218 & 189 \\
\hline david.col & $|\mathrm{V}| / 5$ & 158 & 157 & 153 & 142 & 164 & 152 \\
\hline DSJC125.1.col & $|\mathrm{V}| / 5$ & 255 & 252 & 248 & 238 & 227 & 215 \\
\hline DSJC125.5.col & $|\mathrm{V}| / 5$ & 1091 & 1083 & 1078 & 1073 & 1047 & 1033 \\
\hline DSJC125.9.col & $|\mathrm{V}| / 5$ & 1798 & 1789 & 1794 & 1787 & 1793 & 1785 \\
\hline games120.col & $|\mathrm{V}| / 5$ & 288 & 281 & 282 & 269 & 192 & 181 \\
\hline homer.col & 10 & 662 & 655 & 651 & 625 & 603 & 541 \\
\hline huck.col & $|\mathrm{V}| / 5$ & 130 & 129 & 130 & 126 & 123 & 110 \\
\hline inithx.i.1.col & 10 & 6644 & 6153 & 7412 & 6272 & 6215 & 5838 \\
\hline inithx.i.2.col & 10 & 5622 & 5104 & 5956 & 5831 & 4771 & 4478 \\
\hline inithx.i.3.col & 10 & 5589 & 4756 & 5943 & 5818 & 4804 & 4464 \\
\hline jean.col & $|\mathrm{V}| / 5$ & 111 & 110 & 110 & 104 & 110 & 95 \\
\hline latin_square_10.col & 10 & 85161 & 85072 & 76925 & 76925 & 77031 & 76956 \\
\hline le450_5a.col & 10 & 1824 & 1801 & 1977 & 1923 & 1545 & 1520 \\
\hline le450_5b.col & 10 & 1820 & 1801 & 1969 & 1923 & 1550 & 1522 \\
\hline le450_5c.col & 10 & 2985 & 2951 & 3154 & 3124 & 2578 & 2553 \\
\hline le450_5d.col & 10 & 2943 & 2913 & 3140 & 3108 & 2583 & 2546 \\
\hline le450_15b.col & 10 & 2395 & 2355 & 2795 & 2719 & 2338 & 2268 \\
\hline le450_25b.col & 10 & 2664 & 2606 & 2903 & 2863 & 2382 & 2337 \\
\hline le450_25d.col & 10 & 4872 & 4807 & 5420 & 5376 & 4844 & 4747 \\
\hline miles250.col & $|\mathrm{V}| / 5$ & 185 & 184 & 183 & 172 & 134 & 126 \\
\hline miles500.col & $|\mathrm{V}| / 5$ & 522 & 522 & 502 & 483 & 402 & 367 \\
\hline miles750.col & $|\mathrm{V}| / 5$ & 870 & 870 & 836 & 833 & 708 & 648 \\
\hline miles1000.col & $|\mathrm{V}| / 5$ & 1183 & 1180 & 1114 & 1108 & 1035 & 963 \\
\hline miles1500.col & $|\mathrm{V}| / 5$ & 1645 & 1616 & 1517 & 1513 & 1565 & 1490 \\
\hline mulsol.i.1.col & $|\mathrm{V}| / 5$ & 1697 & 1690 & 1649 & 1649 & 1313 & 1240 \\
\hline mulsol.i.2.col & $|\mathrm{V}| / 5$ & 1685 & 1682 & 1685 & 1668 & 1319 & 1211 \\
\hline mulsol.i.3.col & $|\mathrm{V}| / 5$ & 1695 & 1692 & 1695 & 1669 & 1260 & 1217 \\
\hline mulsol.i.4.col & $|\mathrm{V}| / 5$ & 1704 & 1701 & 1704 & 1693 & 1276 & 1214 \\
\hline mulsol.i.5.col & $|\mathrm{V}| / 5$ & 1714 & 1713 & 1697 & 1686 & 1296 & 1233 \\
\hline myciel3.col & $|\mathrm{V}| / 5$ & 5 & 5 & 5 & 5 & 7 & 7 \\
\hline myciel4.col & $|\mathrm{V}| / 5$ & 21 & 21 & 21 & 20 & 25 & 24 \\
\hline myciel6.col & $|\mathrm{V}| / 5$ & 233 & 231 & 231 & 223 & 247 & 237 \\
\hline myciel7.col & $|\mathrm{V}| / 5$ & 723 & 717 & 714 & 701 & 737 & 711 \\
\hline queen5_5.col & $|\mathrm{V}| / 5$ & 46 & 46 & 46 & 45 & 50 & 48 \\
\hline queen6_6.col & $|\mathrm{V}| / 5$ & 91 & 91 & 91 & 90 & 86 & 82 \\
\hline queen7_7.col & $|\mathrm{V}| / 5$ & 148 & 147 & 148 & 145 & 142 & 136 \\
\hline queen8_8.col & $|\mathrm{V}| / 5$ & 236 & 232 & 236 & 233 & 208 & 201 \\
\hline queen8_12.col & $|\mathrm{V}| / 5$ & 458 & 453 & 458 & 457 & 380 & 369 \\
\hline queen9_9.col & $|\mathrm{V}| / 5$ & 340 & 336 & 336 & 332 & 306 & 293 \\
\hline queen10_10.col & $|\mathrm{V}| / 5$ & 485 & 479 & 485 & 483 & 403 & 394 \\
\hline queen11_11.col & $|\mathrm{V}| / 5$ & 644 & 643 & 650 & 637 & 546 & 536 \\
\hline queen12_12.col & $|\mathrm{V}| / 5$ & 866 & 853 & 866 & 858 & 703 & 689 \\
\hline queen13_13.col & $|\mathrm{V}| / 5$ & 1097 & 1093 & 1106 & 1066 & 910 & 887 \\
\hline queen14_14.col & $|\mathrm{V}| / 5$ & 1407 & 1385 & 1407 & 1403 & 1127 & 1101 \\
\hline queen15_15.col & $|\mathrm{V}| / 5$ & 1721 & 1707 & 1722 & 1703 & 1388 & 1366 \\
\hline queen16_16.col & $|\mathrm{V}| / 5$ & 2107 & 2075 & 2136 & 2125 & 1682 & 1650 \\
\hline school1.col & 10 & 6633 & 6553 & 6975 & 6752 & 5628 & 5398 \\
\hline school1_nsh.col & 10 & 5545 & 5450 & 5721 & 5622 & 4169 & 4066 \\
\hline zeroin.i.1.col & 10 & 1210 & 1198 & 1185 & 1166 & 1454 & 1358 \\
\hline zeroin.i.2.col & 10 & 1135 & 1126 & 1105 & 1079 & 1294 & 1201 \\
\hline zeroin.i.3.col & 10 & 1134 & 1126 & 1107 & 1082 & 1221 & 1158 \\
\hline
\end{tabular}

\section{Conclusions}

In this paper, we propose a memetic algorithm (Memetic_D_O_MLCP) to deal with the minimum load coloring problem. The algorithm employs an improved K-OPT local search procedure with a 
combination of data splitting operation, disturbance operation and a population evolutionary operation to assure the quality of the search results and intensify the searching ability.

We assessed the performance of our algorithm on 59 well-known graphs from the benchmark DIMACS competitions. The algorithm could find the best results of 46 graphs. Compared with simulated annealing algorithm and greedy algorithm, which cover the best results for the tested instances, our algorithm was more competent.

In addition, we investigated the artificial bee colony algorithm, variable neighborhood search algorithm and tabu search algorithm proposed in the literature. We carried out comparative experiments between our algorithm and artificial bee colony algorithm using 21 benchmark graphs, and the experiments showed that the algorithm's best results of 19 benchmark graphs were better than those of artificial bee colony algorithm, and the best-known result of one benchmark graph was improved by our algorithm. More experiments were conducted to compare our algorithm with tabu search algorithm and variable neighborhood search algorithm, and proved that the best-known results of 15 benchmark graphs were improved by our algorithm.

Finally, we showed that the proposed Memetic_D_O_MLCP approach significantly improved the classical heuristic search approach for the minimum load coloring problem.

Author Contributions: Writing and methodology, Z.Z.; Software, Z.Z.; Review and editing, Z.L.; Validation, X.Q.; and Supervision, W.W.

Funding: This research was supported by the Scientific Research Fund of Key Laboratory of Pattern Recognition and Intelligent Information Processing of Chengdu University (No. MSSB-2018-08), Chengdu Science and Technology Program (No. 2018-YF05-00731-SN), Sichuan Science and Technology Program (No. 2018GZ0247), and the Application Fundamental Foundation of Sichuan Provincial Science and Technology Department (No. 2018JY0320).

Conflicts of Interest: The authors declare no conflict of interest.

\section{References}

1. Ahuja, N.; Baltz, A.; Doerr, B.; Přívětivý, A.; Srivastav, A. On the minimum load coloring problem. J. Discret. Algorithms 2007, 5, 533-545. [CrossRef]

2. Baldine, I.; Rouskas, G.N. Reconfiguration and dynamic load balancing in broadcast WDM Networks. Photonic Netw. Commun. J. 1999, 1, 49-64. [CrossRef]

3. Rouskas, G.N.; Thaker, D. Multi-destination communication in broadcast WDM networks: A Survey. Opt. Netw. 2002, 3, 34-44.

4. Fei, T.; Bo, W.; Jin, W.; Liu, D. Artificial Bee Colony Algorithm for the Minimum Load Coloring Problem. J. Comput. Theor. Nanosci. 2013, 10, 1968-1971. [CrossRef]

5. Ye, A.; Zhang, Z.; Zhou, X.; Miao, F. Tabu Assisted Local Search for the Minimum Load Coloring Problem. J. Comput. Theor. Nanosci. 2014, 11, 2476-2480. [CrossRef]

6. Gutin, G.; Jones, M. Parameterized algorithms for load coloring problem. Inf. Process. Lett. 2014, 114, 446-449. [CrossRef]

7. Barbero, F.; Gutin, G.; Jones, M.; Sheng, B. Parameterized and Approximation Algorithms for the Load Coloring Problem. Algorithmica 2017, 79, 211-229. [CrossRef]

8. Hansen, P.; Mladenović, N.; Urošević, D. Variable neighborhood search for the maximum clique. Discret. Appl. Math. 2004, 145, 117-125. [CrossRef]

9. Dražić, Z.; Čangalović, M.; Kovačević-Vujčić, V. A metaheuristic approach to the dominating tree problem. Optim. Lett. 2017, 11, 1155-1167. [CrossRef]

10. Fadlaoui, K.; Galinier, P. A tabu search algorithm for the covering design problem. J. Heuristics 2011, 17, 659-674. [CrossRef]

11. Li, X.; Yue, C.; Aneja, Y.P.; Chen, S.; Cui, Y. An Iterated Tabu Search Metaheuristic for the Regenerator Location Problem. Appl. Soft Comput. 2018, 70, 182-194. [CrossRef]

12. Ho, S.C. An iterated tabu search heuristic for the Single Source Capacitated Facility Location Problem. Appl. Soft Comput. 2015, 27, 169-178. [CrossRef] 
13. Palubeckis, G.; Ostreika, A.; Rubliauskas, D. Maximally diverse grouping: An iterated tabu search approach. J. Oper. Res. Soc. 2015, 66, 579-592. [CrossRef]

14. Tang, Z.; Feng, Q.; Zhong, P. Nonuniform Neighborhood Sampling based Simulated Annealing for the Directed Feedback Vertex Set Problem. IEEE Access 2017, 5, 12353-12363. [CrossRef]

15. Palubeckis, G. A variable neighborhood search and simulated annealing hybrid for the profile minimization problem. Comput. Oper. Res. 2017, 87, 83-97. [CrossRef]

16. Zhao, D.; Shu, Z. A Simulated Annealing Algorithm with Effective Local Search for Solving the Sum Coloring Problem. J. Comput. Theor. Nanosci. 2016, 13, 945-949. [CrossRef]

17. Li, X.; Li, S.-J.; Li, H. Simulated annealing with large-neighborhood search for two-echelon location routing problem. Chin. J. Eng. 2017, 39, 953-961.

18. Parekh, A.K. Analysis of a greedy heuristic for finding small dominating sets in graphs. Inf. Process. Lett. 1991, 39, 237-240. [CrossRef]

19. Katayama, K.; Hamamoto, A.; Narihisa, H. An effective local search for the maximum clique problem. Inf. Process. Lett. 2005, 95, 503-511. [CrossRef]

20. Battiti, R.; Protasi, M. Reactive local search for maximum clique. Algorithmica 2001, 29, 610-637. [CrossRef]

21. Xu, J.; Wu, C.C.; Yin, Y.; Lin, W.C. An iterated local search for the multi-objective permutation flowshop scheduling problem with sequence-dependent setup times. Appl. Soft Comput. 2017, 52, 39-47. [CrossRef]

22. Pullan, W. Phased local search for the maximum clique problem. J. Comb. Optim. 2006, 12, $303-323$. [CrossRef]

23. Moscato, P.; Cotta, C. A gentle introduction to memetic algorithms. In Handbook of Metaheuristics; International series in operations research and management science; Kluwer Academic Publishers: Dordrecht, The Netherlands, 2003; Volume 57, pp. 105-144, Chapter 5.

24. Jin, Y.; Hao, J.K.; Hamiez, J.P. A memetic algorithm for the Minimum Sum Coloring Problem. Comput. Oper. Res. 2014, 43, 318-327. [CrossRef]

(C) 2019 by the authors. Licensee MDPI, Basel, Switzerland. This article is an open access article distributed under the terms and conditions of the Creative Commons Attribution (CC BY) license (http://creativecommons.org/licenses/by/4.0/). 